\title{
Quartäre Sedimente auf der Atlantik-Insel Porto Santo (Madeira-Archipel) und ihre paläoklimatische Deutung
}

\author{
Von J. Lietz und M. Schwarzbach, Köln
}

Mit 10 Abbildungen

\begin{abstract}
$\mathrm{Z}$ us a m menf assung. Auf der kleinen Atlantik-Insel Porto Santo (Madeira-Archipel) bedecken ausgedehnte quartäre Ablagerungen vielfach den tertiären, meist vulkanischen Sockel. A ol in i t e, d. h. Dünenbildungen aus z. T. regelmäßig schräggeschichteten marin-bioklastischen Kalkareniten, werden bis $50 \mathrm{~m}$ mächtig; sie führen (ebenso wie andere quartäre Ablagerungen) Landschnecken (Fossil-Liste, V). Als Ausblasungsgebiet ist der weit ausgedehnte Schelf zu betrachten, der in den Glazialen trockenlag. Die Aolinite sind also kaltzeitlich und ergaben entsprechende C14-Alter (21.570 und 13.480 B.P., jüngeres Würm). Auf die andersartige neuere Deutung der Bermudas-Aolinite durch Bretz u. a. wird kurz eingegangen. Die Äolinite sind durch autochthone und allochthone $\mathrm{B}$ ö de n (Braunlehme, rötliche Kalksandböden) in drei Abschnitte geteilt. Im Liegenden finden sich ebenfalls Braunlehme. Kollu vium, d. h. geringfügig verfrachtetes Schuttmaterial, tritt als Gehängeschutt und als Ausfüllung flacher Depressionen auf. Es führt gleichfalls Landschnecken und ist z. T. mit den Äoliniten verzahnt, d. h. gleichfalls kaltzeitlich.
\end{abstract}

Nur eine $\mathrm{Strandterrasse}$ ist nachzuweisen. Sie ist als Brandungskonglomerat ausgebildet, führt eine marine Fauna und liegt $0-3 \mathrm{~m}$ über NN; C14-Alter: $\geqq 40.000$ a. Vielleicht gehört sie ins Tyrrhen III (Letztes Interglazial). - Z stratigraphische Eingliederung der flachen alten Täler ist nicht möglich, die junge Zerschluchtung ist nicht älter als Würm. Die Steilküste ist jung und durch Brandungserosion geformt. An der $\mathrm{N}$-Küste könnte die rückschreitende Erosion maximal $12 \mathrm{~cm} / \mathrm{a}$ betragen.

Das K li m a der Glazialzeiten (mit Aolinit- und Kolluvialbildungen) war kühler als heute und vermutlich relativ trocken - also nicht pluvial; die Winde wehten aus mehr westlicher Richtung als heute.

Eine genauere stratigraphische Einordnung des Quartärs ist nur z. T. möglich: die obersten Äolinite und ein Teil des Kolluviums sind jüngeres Würm. Die tieferen Äolinite können älteres Würm oder Prä-Würm sein.

S u m m a ry. Quaternary sediments frequently cover the Tertiary, mostly volcanic base of the small Atlantik island of Porto Santo (Madeira Archipelago). Eolianites, i. e. dunes of crossbedded marine-bioclastic calcarenite, up to $50 \mathrm{~m}$ thick, contain land-snails (list V). The sand was blown out from the large shelf of the island fallen dry during glacial times. Therefore the eolianites are of glacial age, in accordance with the C14-data of 21,570 and 13,480 B. P. (main Würm). The opposite opinion of BRETz etc. for the Bermudas is shortly discussed. - Soils or soil sediments (brown loam, reddish calcareous soils) allow a 3-fold division of some eolianites. Brown loam is to be found also below the eolianites.

Colluvial sediments mantle steep slopes and fill flat depressions. They too contain landsnails and interfinger with the eolianites. Therefore they are also of glacial age.

We only found one marine conglomeratic terrace, $0-3 \mathrm{~m}$ above sea-level with marine fossils; the C14-age is: $\geqq 40,000$ B. P., perhaps Tyrrhen III (last Interglacial). - There are 2 valley systems, one rather old, the other young, Würm or Post-Würm). The cliff coast is also young and was formed by wave erosion; velocity of recession perhaps $12 \mathrm{~cm} / \mathrm{a}$ or less.

The climates of the glacial times (with eolianites and colluvium) were cooler than today and presumably dry (i.e. not pluvial). Winds came more from the West than now. The upper eolianites are younger Würm but the age of the older sediments is not yet clear. They could be of Würm or Prä-Würm age.

\section{Einführung}

Die kleine portugiesische Atlantik-Insel Porto Santo liegt unter $33^{\circ} 4^{\prime} \mathrm{n}$. Br. und $16^{\circ} 20^{\prime}$ w. L. (Abb. 1). Sie ist nur $50 \mathrm{~km}^{2}$ groß und gehört zusammen mit der weit größeren und bekannteren, $45 \mathrm{~km}$ entfernten Nachbarinsel Madeira und den unbewohnten Desertas zum Madeira-Archipel. Mit Lissabon besteht regelmäßige Flugverbindung. 
Porto Santo besitzt ein niedriges Relief. Im Mittelteil der Insel liegen auffällige Verebnungen mit Durchschnittshöhen von $50-80 \mathrm{~m}$. Der nördliche und südliche Teil dagegen sind bergig. Die höchste Erhebung ist der Pico do Facho mit $517 \mathrm{~m}$. Im W, N und E wird Porto Santo von Steilküsten begrenzt, die stellenweise bis $\mathrm{zu} 100 \mathrm{~m}$ über den Meeresspiegel aufragen. Nur im SE ist eine Flachküste mit Sandstrand ausgebildet. Während der Sommermonate herrscht auf Porto Santo große Trockenheit (Jahresniederschlag $350 \mathrm{~mm}$ ). Die Insel ist daher wasserarm und nur spärlich mit Vegetation bedeckt (Abb.2).
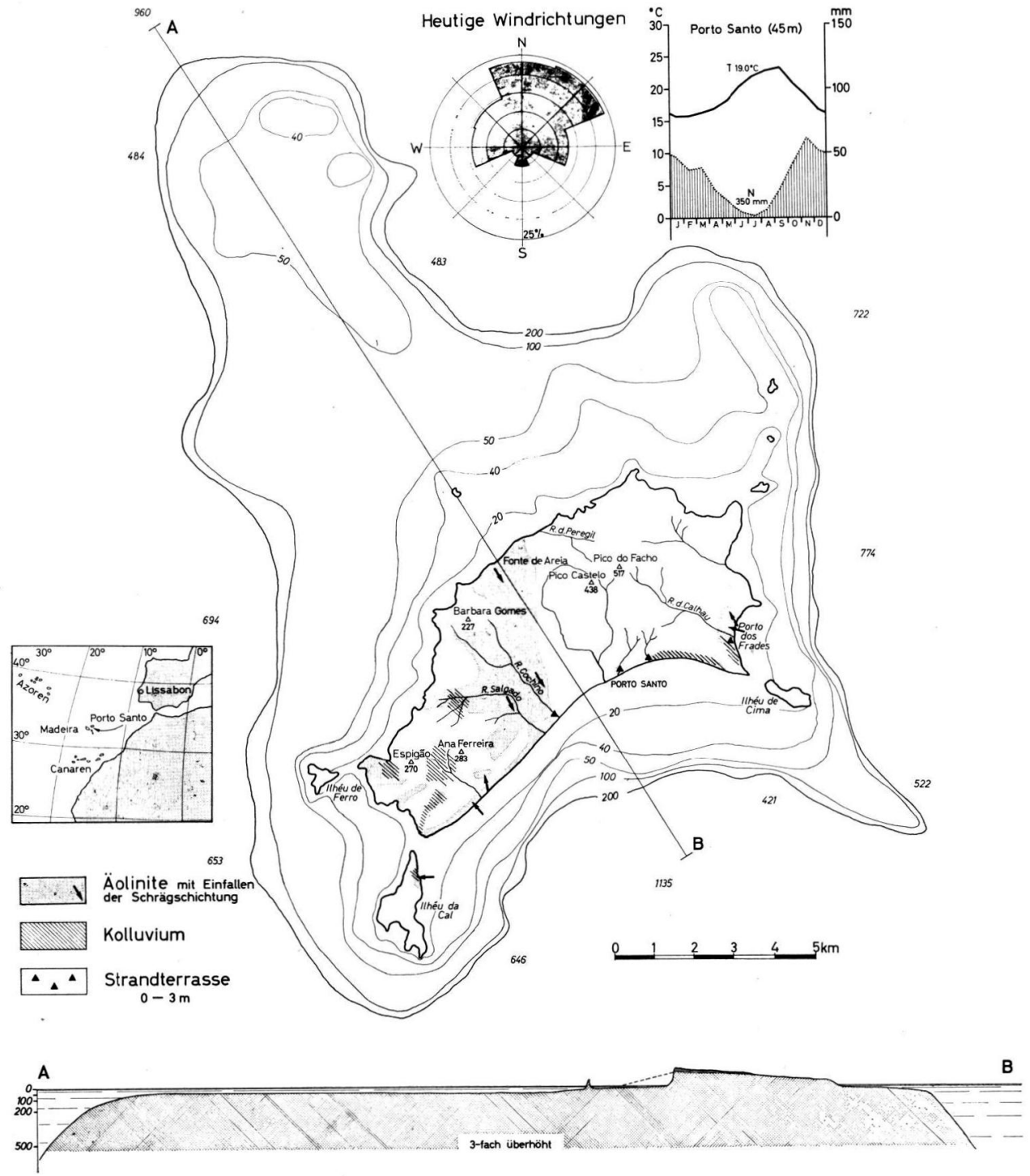

Abb. 1. Verbreitung des Quartärs auf Porto Santo, Tiefenkarte des Schelfes, heutiges Klima. Ein weiter Schelf als glaziales Auswehungsgebiet für die Äolinite. Das Profil zeigt die Lage der Aolinite auf der hohen Steilküste von Fonte de Areia. Die Anwehung erfolgte von NW her. Die gestrichelte Linie gibt eine mögliche Böschung der ursprünglichen Küste von $3^{\circ}$ an. 


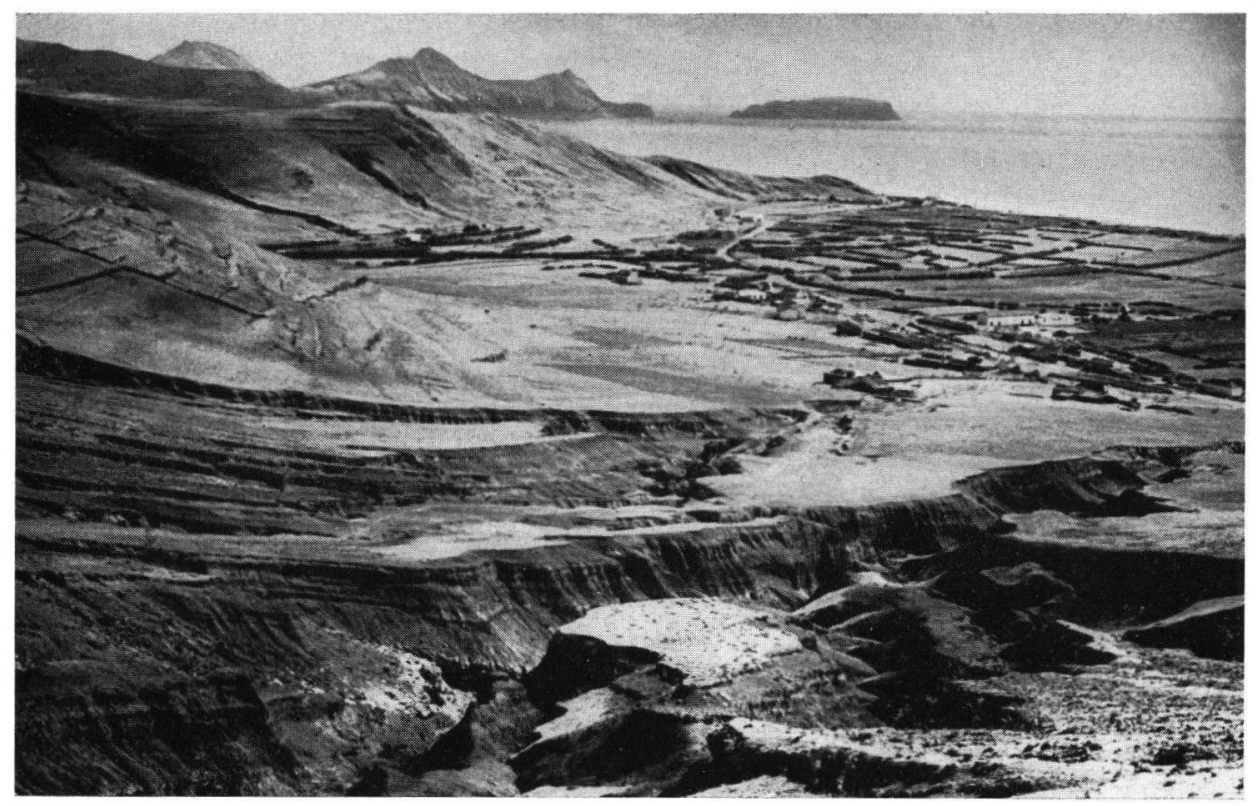

Abb. 2. Blick von oberhalb Ponta (SW Ana Ferreira) gegen NE. Vorn geschichtete Schuttsedimente, oberflächlich etwas kalkzementiert, mit junger Zerschluchtung. Am Grund der Schluchten tertiäre Vulkanite (z. T. mit marinen Einschaltungen). Rechts die Niederung von Ponta mit dem Sandstrand, der sich jenseits des Bergrückens (Cabeço da Ponta) bis Porto Santo hinzieht (nicht sichtbar). Im Hintergrund Steilküste östl. von Porto Santo (in der Mitte Pico dos Maçaricos, $285 \mathrm{~m}$ ): tertiäre Vulkanite mit Schleppen von Gehängeschutt, durch Küstenerosion scharf abgeschnitten (Profil Abb. 10a!). Vor der Küste Ilhéu de Cima.

Im wesentlichen wird Porto Santo aus vulkanischen Gesteinen aufgebaut; aus basaltischen und trachytischen Laven, Tuffen und einer großen Zahl von Gängen. Junge Vulkane, wie sie auf anderen Atlantik-Inseln (schon auf dem nahen Madeira) auftreten, fehlen. Die vulkanischen Gesteine sind z. T. stark zersetzt und weitgehend abgetragen; sie gehören mindestens $z$. T. ins Tertiär, wie sich aus eingeschalteten fossilführenden miozänen Sedimenten ergibt. Wir konnten den wenigen bekannten Fundpunkten fossilführenden Miozäns 11 neue hinzufügen (Lietz \& Schwarzbach 1970). Aufgrund der im Miozän vorherrschenden Korallenkalk-Fazies ist anzunehmen, daß dieser Zeitabschnitt mit einem etwas wärmeren Klima als heute eine längere Ruhepause innerhalb der vulkanischen Aufbauphase von Porto Santo darstellt.

Die quartären Bildungen bedecken knapp ein Drittel der Fläche von Porto Santo (Abb. 1). $\mathrm{Zu}$ ihnen gehören äolische Kalkarenite (Äolinite), grob- und feinklastische Schuttbildungen (Kolluvium), fossile Bodenbildungen sowie eine fossile Strandterrasse. Vielfach liegen die quartären Bildungen bereits flächenhaft eingeebneten tertiären Vulkaniten auf. Ihre maximale Mächtigkeit dürfte über $50 \mathrm{~m}$ nicht hinausgehen.

Eine gründliche ältere geologische Beschreibung der Insel stammt von G. HARTUNG (1864). Eine Monographie der Ilhas de Zargo ${ }^{1}$ ) veröffentlichte E. C. N. Pereira (1956); hauptsächlich petrographische Untersuchungen der Vulkanite J. C. DE MoRAIs (1943). In neuerer Zeit hat von deutschen Geologen mehrere Beiträge K. KREJCI-Graf (1951, 1960, 1961a, 1961b, 1964) geliefert.

1) Der Portugiese Zargo gilt als Entdecker der Madeira-Inseln. 
Unsere Arbeiten auf Porto Santo wurden hauptsächlich im September-Oktober 1968 durchgeführt. Erste Untersuchungen begann M. SсHWARzbach im Sommer 1967. Im September 1969 wurden die Geländearbeiten durch J. LIETZ abgeschlossen.

\section{II. Äolinite}

Der Begriff „Äolinit“ (engl. eolianite) wurde von SAyles (1931) nach der Bearbeitung pleistozäner Dünen auf den Bermudas allgemein für verfestigte Dünenbildungen eingeführt, unabhängig von ihrem Alter und ihrem Stoffbestand. Heute ist dieser Begriff nur noch für pleistozäne, küstengebundene Dünenbildungen geläufig, die überwiegend aus klastischem Kalkmaterial aufgebaut werden („eolian calcarenite“, „coastal limestone“; Fairbridge 1967, S. 407, SAnders \& Friedmann 1967, S. 231). Butzer (1964, S. 217) schränkte den Begriff "Äolinit“ noch stärker ein, indem er ihn nur auf "consolidated regressional dunes" bezog. Diese Einschränkung ist aber nicht empfehlenswert, weil gerade die Äolinite von der Typlokalität (den Bermudas) von einigen Bearbeitern heute nicht mehr als Bildungen von Regressionsdünen aufgefaßt werden (BRETZ 1960, MACKENZIE 1964, LAND et al. 1967). Im deutschen Sprachgebrauch ist das Wort bisher kaum üblich. $\left.{ }^{2}\right)$

\section{A 11 gemeine Kennzeichen}

Auf Porto Santo nehmen die bis zu $50 \mathrm{~m}$ mächtigen, gelblich-weißen Aolinite unter den quartären Sedimenten den größten Raum ein. Insgesamt bedecken sie eine Fläche von ca. $15 \mathrm{~km}^{2}$. Sie sind nicht nur im unmittelbaren Küstenbereich, sondern auch im Zentralteil der Insel verbreitet. Ihre Basis wird zum größten Teil von den Gesteinen des vulkanischen Untergrundes und deren Verwitterungsprodukten, nur lokal (E- und SE-Küste) von verfestigten Brandungskonglomeraten gebildet. Die Höhenlage der Basis ist auf beiden Längsküsten der Insel sehr verschieden. Während die Äolinite im NW einer bis zu $100 \mathrm{~m}$ hohen Steilküste auflagern, tauchen sie an der E- und SE-Küste unter den Meeresspiegel ab. Sämtliche Äolinitvorkommen sind durch Böden, Bodensedimente oder Schutteinlagerungen gegliedert.

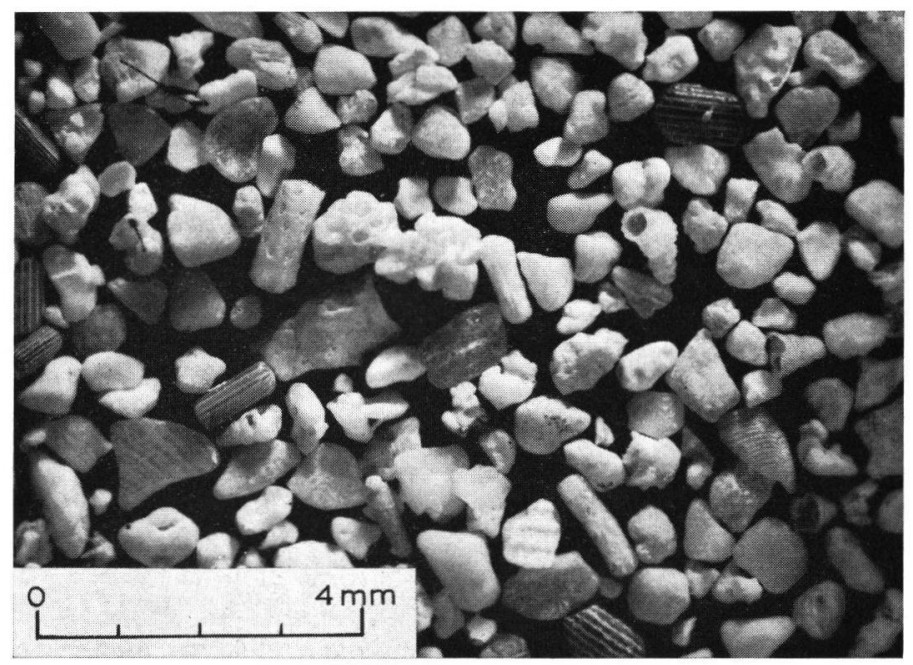

-Abb. 3. Streupräparat eines Äolinits (Abschn. A, Fonte de Areia). Kalkkörner z. T. gut gerundet, z. T. nur angerundet. Die biogene Herkunft ist vielfach deutlich erkennbar.

2) Wo es vereinzelt gebraucht wird, findet man die Schreibweise „Aolianit“ (z. B. KLUG 1968). Wir möchten diese aus dem Englischen übernommene Schreibweise nicht empfehlen. „Eolianite“ ist dem englischen „eolian“ angepaßt. Im Deutschen heißt es aber äolisch (vom Äolus abgeleitet), und ein entsprechendes Substantiv sollte also Äolinit heißen. 
Die Kalkarenite sind überwiegend $\mathrm{schräggeschichtet} \mathrm{(vgl.} \mathrm{Profilbeschreibung} \mathrm{NW-}$ Küste und Abb. 8). Umfang und Form der Schrägschichtung sind allerdings stark vom jeweiligen Relief des Untergrundes abhängig. Die schräggeschichteten Kalkarenite sind $\mathrm{se} h \mathrm{r}$ re in. Bis auf einen salzsäureunlöslichen Anteil von durchschnittlich nur $3 \%$ bestehen sie aus kalkigem Skelettmaterial mariner Organismen (Abb. 3). Neben körnigem Kalkalgengrus sind Schalenreste und Hartteile von Muscheln, Schnecken, Echinodermen, Bryozoen und vereinzelten Foraminiferen vertreten. Viele Kalkpartikel sind an ihrer Oberfläche so stark abgeschliffen, daß sich ihr Ausgangsmaterial nicht mehr identifizieren läßt. Nur im Schliffbild wird bei einigen die organische Struktur noch sichtbar.

Der Rundungsgrad der Kalkkörner ist nicht einheitlich. Gut gerundete finden sich neben angerundeten oder noch völlig eckigen Bruchstücken. Insgesamt überwiegt die angerundete Kornform. Die Korngrößenverteilung der Kalkarenite erstreckt sich vom Grobsand- bis zum Siltbereich. Die dabei auftretenden Sortierungswerte bezeichnen die Aolinite im allgemeinen als noch gut bis mäßig sortierte Sedimente.

$\mathrm{R}$ öntgenographis ch lassen sich im Karbonatanteil der Kalkarenite Aragonit, Kalzit und $\mathrm{Mg}-\mathrm{Kalzit}$ nachweisen. Sekundäre Dolomitisierung, wie sie von Kalkareniten der Kanarischen Inseln bekannt ist (MüLler \& Tietz 1966, Rothe 1968), konnte nicht festgestellt werden, auch nicht innerhalb der Sprühzone der Brandung. Ebenso ist keine auffallende Veränderung des Aragonit- oder Mg-Kalzitgehaltes im Vertikalprofil der Äolinite erkennbar.

Der salzsäureunlösliche Anteil der Kalkarenite besteht aus vulkanischen Gesteinsfragmenten, Pyroxenen, Hornblenden, Olivinen, Feldspäten und Mineralen der Zeolithgruppe. Durch Anlösung sind die Oberflächen der Schwermineralkörner häufig fein gezähnelt.

Der Verfestigungsgrad der Kalkarenite ist unterschiedlich. In der Regel ist die Matrix nur ein feiner Kalzitstaub, der sie bei Druckeinwirkung ziemlich leicht zerfallen läßt. An Wetterseiten oder in Küstennähe (besonders innerhalb der Sprühzone der Brandung) sind die Kalkarenite dagegen meistens sehr viel mehr verhärtet. Tapetenartige Oberflächenverkrustungen verschleiern hier oft das innere Gefüge.

Der typische Fossilinhalt der Aolinite sind $\mathrm{L}$ a ndschnecken. In den schräggeschichteten Partien treten sie jedoch bei weitem nicht so zahlreich auf, wie in den eingelagerten rötlichen Kalksandböden. In der Fossil-Liste (V) sind Formen aus den Äoliniten aufgeführt. Außer dem Hinweis auf das teilweise pleistozäne Alter kommt den Landschnecken aber kein besonderer stratigraphischer Leitwert zu. Neben Landschnecken findet man - besonders an der heutigen Oberfläche der Aolinite - aus Kalk bestehende ast- und zylinderförmige Gebilde, die von KreJCI-Graf (1961 a) als „versteinerte Büsche“ gedeutet werden. Die Voraussetzung für eine Kalkkonkretionierung sieht er in klimatischen Verhältnissen, bei denen Aszendenz und Deszendenz von Lösungen gleich stark ausgeprägt waren. ${ }^{3}$ )

\section{Profilbeschreibungen}

Gebietsweise sind zwar untereinander vergleichbare Äolinitprofile aufgeschlossen, aber Sedimentationsart und Reliefeinflüsse bewirkten, daß die Ausbildung insgesamt unterschiedlich ist. Die Aufstellung eines Gesamtnormalprofiles für die fossilen Dünen ist deshalb nicht möglich. Ihr Aufbau soll im folgenden an einzelnen Profilen in den wichtigsten Verbreitungsgebieten erläutert werden.

Áolinite an der NW-Küste

An der NW-Küste sind die Äolinite eindrucksvoll durch das Küstenprofil von Fonte de Areia („Sandquelle“) erschlossen (Abb. 4 u. 6a). Sie verfüllen hier zwischen Cabeço Barbara Gomes $(226 \mathrm{~m})$ und der Mündungsschlucht des Rib. do Peregil eine $2 \mathrm{~km}$ breite Eintiefung im vulkanischen Untergrund. Zusammen mit den Vulkaniten bilden die Äolinite eine über $100 \mathrm{~m}$ hohe, schroff ins Meer abfallende Steilküste.

3) Außerdem erwähnt KrejCI-Graf (1960) aus Äoliniten der NW-Küste nach Angaben von Pereira (1956, S. 160) den Fund eines Eies „von der Gestalt eines Enteneis“. Aus dieser Angabe lassen sich aber wohl kaum sichere Schlüsse ziehen. - An dieser Stelle sei auch auf C. G. EHRENBERG hingewiesen, der 1854 in seiner "Mikrogeologie“ bereits Diatomeen aus Landschneckenführender "Erde" von Porto Santo nachwies. Doch lassen sich die Fundschichten nicht genauer identifizieren. Wir verdanken den Hinweis Herrn P. BENEdeK (Köln). 


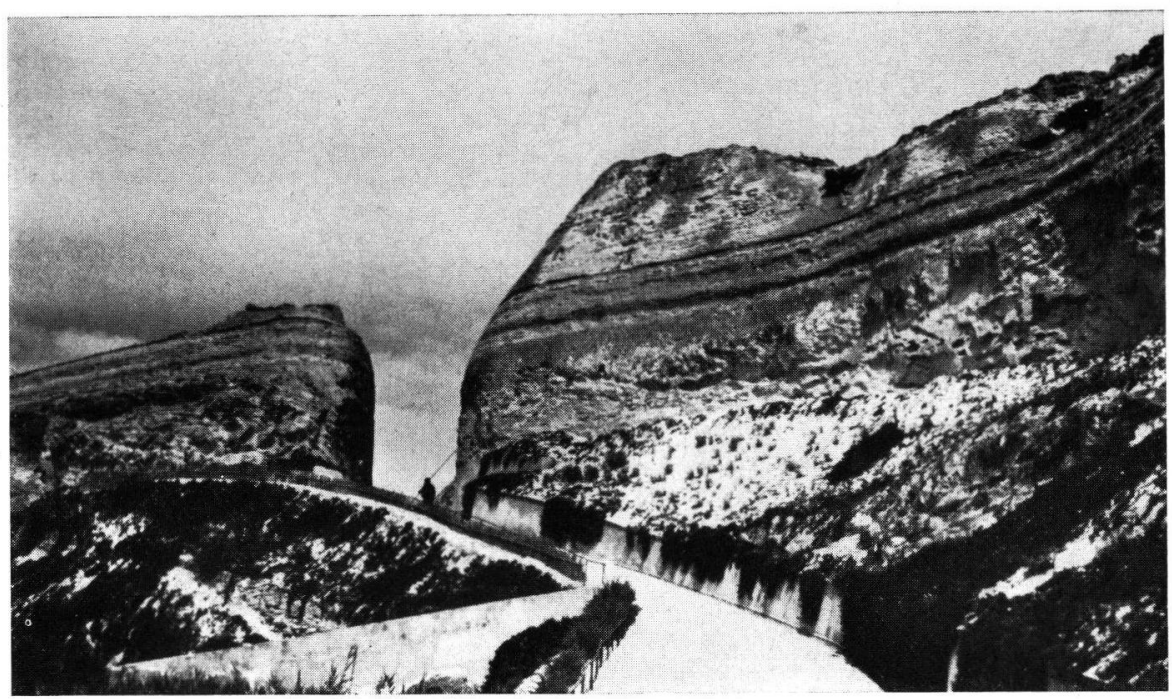

Abb. 4. Fonte de Areia: Aolinite B u. C, dazwischen rötliche Kalksandböden; vgl. auch Abb. 6 a.

\begin{tabular}{|c|c|c|c|}
\hline e $e$ & Landschnecken & 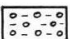 & geschichtete Talfüllung \\
\hline VIIIIIIIIIII & Kalkzementation & $\begin{aligned} 00 \cdots 00 \\
0.00\end{aligned}$ & Kolluvium \\
\hline 1,164 & $\begin{array}{l}\text { Boden an der } \\
\text { heutigen Oberfläche }\end{array}$ & $\because \because 8$ & Äolinit, z.T. schräggeschichtet \\
\hline 20 & rötı. Kalksandboden & 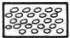 & marine Strandterrasse \\
\hline $\left.7^{7}\right\}^{5,09}$ & umgelagerter Braunlehm & $\infty 0^{\circ}$ & Vulkanit-Gerölle \\
\hline i;?; 37,3 & Braunlehm & $v_{v} v^{2} v$ & tertiärer Vulkanit \\
\hline
\end{tabular}

Abb. 5. Legende zu den Abb. 6, 7 u. 10.

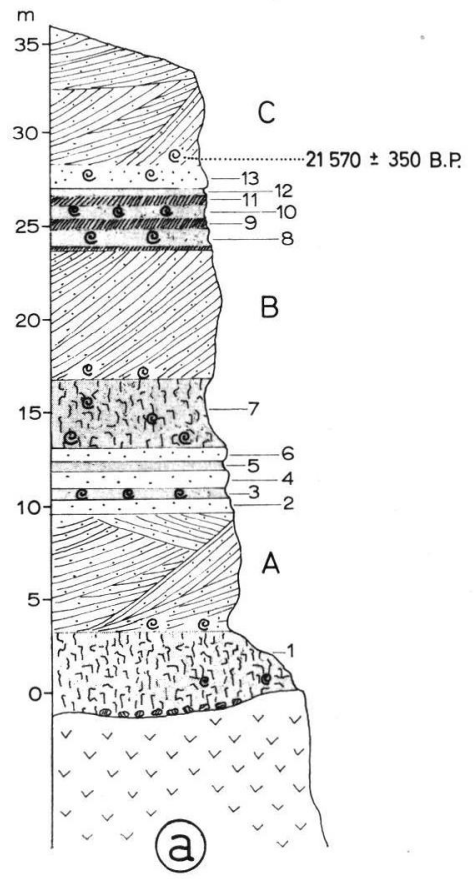

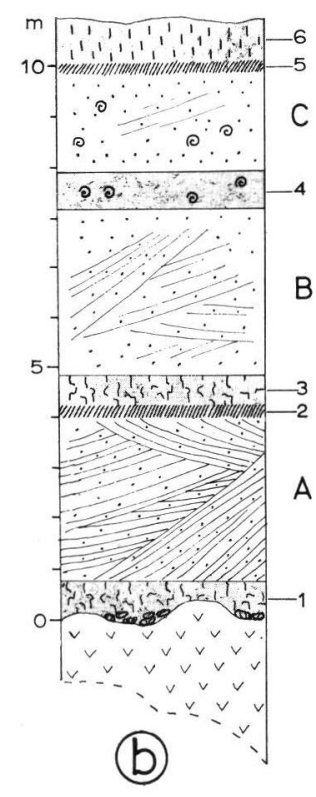

Abb. 6. Aolinit-Profile mit Bodenbildungen. a. Fonte de Areia (vgl. auch Abb. 4); b. Rib. Cochino, westl. Potinhas. (Legende Abb. 5.) 
Das Profil setzt in Höhe der Quellfassung ca. $70 \mathrm{~m}$ über NN ein. Es zeigt drei, bis zu $8 \mathrm{~m}$ mächtige, schräggeschichtete Kalkarenit-Abschnitte $(\mathrm{A}-\mathrm{C})$, die durch ungeschichtete, schwach nach SE geneigte Einschaltungen deutlich voneinander getrennt werden. Bei diesen Einschaltungen handelt es sich teilweise um umgelagertes Bodenmaterial. Dazu gehören ungeschichtete Kalkarenite $(2,4,6,13)$, ein grün-grauer Tonhorizont (7) sowie mehrere rötlich-braun und grau gefärbte Kalksandhorizonte (3, 5, 8-12). Ein grün-grauer Tonhorizont (1) bildet auch das Liegende der Äolinite. An seiner Basis markieren grobe Vulkanitschotter eine scharfe Grenze zu dem flächenhaft eingeebneten vulkanischen Sockel.

Die typisch äolische Schrägschichtung der Kalkarenite ist im Abschnitt B am besten aufgeschlossen. Sie ist von dem darunter liegenden Tonhorizont scharf abgesetzt und bis zum Hangenden nahezu parallel ausgebildet. Einzelne Schichtblätter erreichen dabei eine aufgeschlossene Gesamtlänge bis zu $10 \mathrm{~m}$. Die Ebenflächigkeit der Schichtblätter wird vermutlich dadurch hervorgerufen, daß der gesamte Abschnitt im Hangenden flächenhaft erodiert ist. Das Einfallen der Schrägschichtung ist in allen drei Abschnitten mit Neigungswinkeln zwischen 20-32 generell ähnlich nach SE gerichtet. Mit dem Auskeilen der schräggeschichteten Einheiten zu den Rändern der Depression hin wird die Schrägschichtung unregelmäßiger. Kleinere schräggeschichtete Einheiten, Schichtungsdiskordanzen und wechselnde Einfallsrichtungen lösen hier die regelmäßigeren Formen im Innern der Eintiefung ab. Die den Abschluß bildenden Kalkarenite (C) sind bereits überwiegend zu lockerem Kalksand zerfallen und stellenweise sogar wieder zu flachen Dünenrücken zusammengeweht.

\section{Aolinite im Zentralteil der Insel}

Die Aolinite im Zentralteil der Insel sind an breite, NW-SE gerichtete Depressionen im vulkanischen Untergrund geknüpft. In ihnen lassen sich die Kalkarenite quer über die ganze Insel von Küste zu Küste verfolgen. Da der vulkanische Untergrund jedoch ein sehr unausgeglichenes Relief besitzt, ist eine durchgehende Profilaufnahme nicht möglich. Den besten Einblick bieten die Taleinschnitte des Rib. Salagado und des Rib. Cochino.

Ein Profil im Oberlauf des Rib. Cochino (Abb. 6 b) zeigt ähnlich wie bei Fonte de Areia über tonigen, grüngrauen Verwitterungsprodukten der Vulkanite (1) drei Kalkarenitabschnitte $(\mathrm{A}, \mathrm{B}, \mathrm{C})$, die durch rotbraune Böden $(3,4)$ voneinander getrennt sind. Ein weiterer Bodenhorizont (6) bildet als heutige Oberfläche den Abschluß.

In den beiden unteren Kalkarenitabschnitten ist die Schrägschichtung zwar immer noch vorhanden, aber nicht mehr so deutlich erkennbar wie in den Küstenprofilen. Im oberen Abschnitt kennzeichnen Gerölleinlagerungen und zusammengeschwemmte Landschneckengehäuse stellenweise Umlagerungen. Je nach dem Relief des Untergrundes schwankt die Mächtigkeit in den einzelnen Kalkarenitabschnitten erheblich.

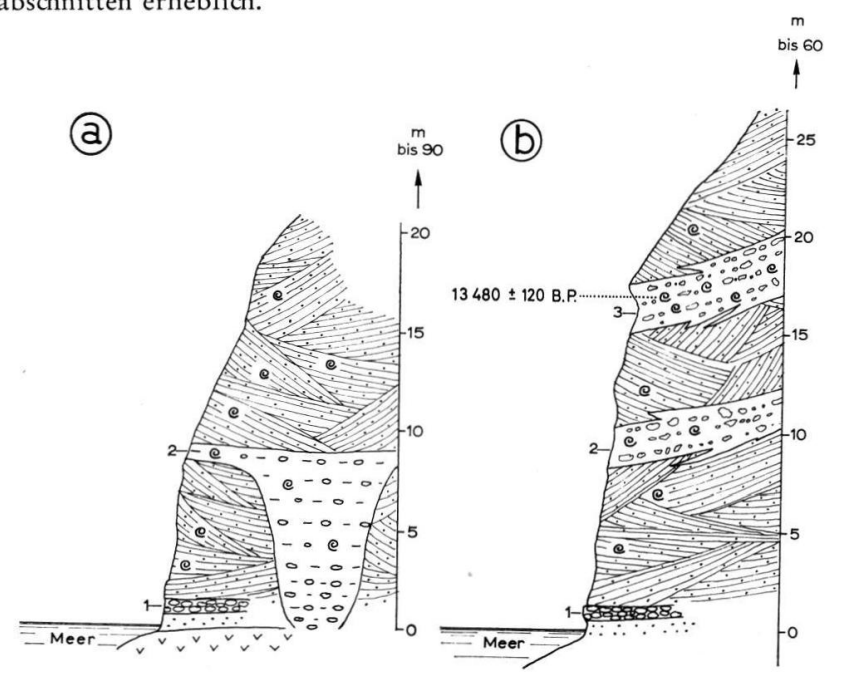

Abb. 7. Aolinit-Profile nördl. (a) u. südl. (b) von der Mündung der Rib. da Calhau bei Porto dos Frades mit kolluvialen Einlagerungen. (Legende Abb. 5.) 


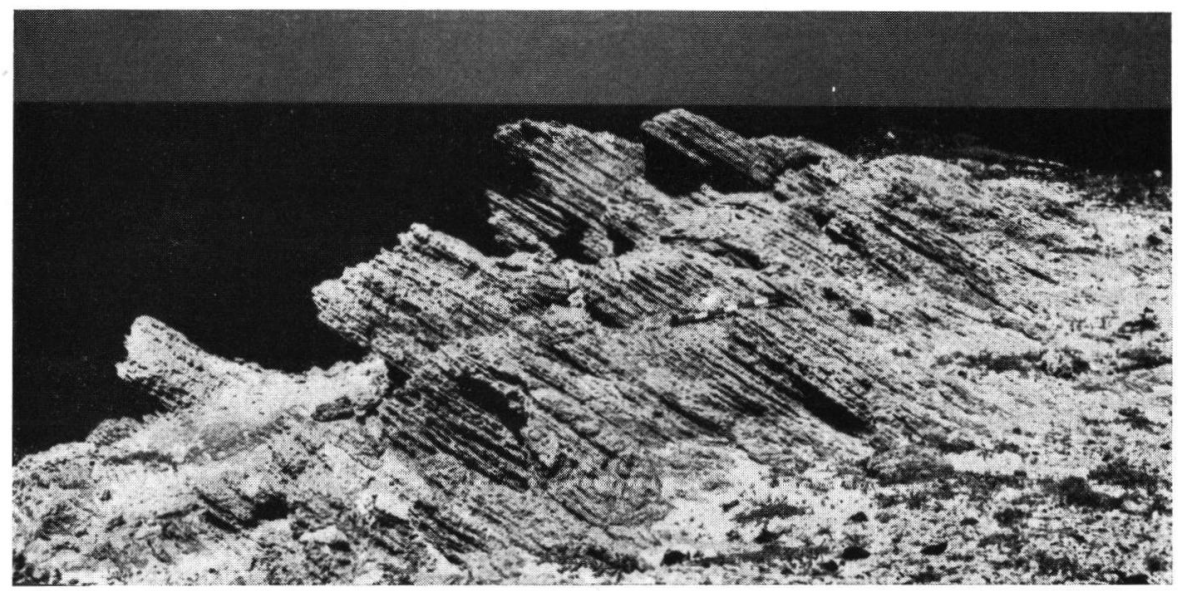

Abb. 8. Schrägschichtung im Äolinit (nach W geneigt; Porto dos Frades).

\section{A olinite an der E-Küste}

Für die Rekonstruktion der Bildungsbedingungen der Aolinite ist ein wichtiges Profil an der E-Küste von Porto Santo in der kleinen Bucht Porto dos Frades aufgeschlossen (Abb. 7). Die Kalkarenite verkleiden hier den S-Hang des Pico Concelho bis zu einer Höhe von $90 \mathrm{~m}$ und ziehen auch noch am E-Hang des Pico do Baixo und des Pico dos Macaricos bis zu $60 \mathrm{~m}$ über den Meeresspiegel hinauf. Die Basis der Äolinite bildet in Meereshöhe ein bis $1 \mathrm{~m}$ mächtiges verfestigtes Brandungskonglomerat (1), das seewärts unter den Meeresspiegel abtauchenden Kalkareniten aufliegt. Das fossilreiche Konglomerat gehört zu einer pleistozänen Strandterrasse, die in dieser Höhenlage noch an verschiedenen Stellen der E- und SE-Küste von Porto Santo ausgebildet ist (vgl. VI).

Ahnlich wie bei Fonte de Areia sind auch bei Porto dos Frades die schräggeschichteten Aolinite durch flachlagernde Einschaltungen unterbrochen. Allerdings handelt es sich hierbei nicht um Böden oder Bodensedimente, sondern um grobklastische Schutteinschwemmungen. Zwei verschiedene Typen lassen sich unterscheiden: nördlich des Rib. do Calhau (Abb. 7a) ist mit scharfer Erosionsgrenze Kalkarenitmaterial und vulkanischer Verwitterungsschutt in Form einer Talfüllung in einen unteren Äolinitabschnitt eingelagert; südlich der Flußmündung (Abb. 7 b) sind es mit breiter Verzahnungsfront in den unteren und höheren Äoliniten rotbraune, grobklastische Einlagerungen vom Typ des Gehängeschuttes.

Schrägschichtung ist in den Aoliniten zwar deutlich ausgeprägt (Abb. 8), aber im allgemeinen nicht so richtungskonstant wie an der NW-Küste. Schichtungsdiskordanzen und wechselnde Einfallsrichtungen treten mehr in den Vordergrund. Offensichtlich spiegelt sich hier in den Lagerungsformen eine größere Abhängigkeit vom nahen Relief des vulkanischen Untergrundes wider.

A olinite an der SE-K üste

Im Bereich des breiten Sandstrandes der SE-Küste treten die Äolinite flächenmäßig zwar stark zurück, lassen sich aber in Erosionsresten bis an die S-Spitze von Porto Sando verfolgen. Sie bilden hier vielfach den Kern der flachen rezenten Dünen oder durchspießen als harte Rippen die Strandsande. Die heutigen Strandsande sind lediglich ein Aufarbeitungsprodukt der hier unter den Meeresspiegel abtauchenden Äolinite. Große Flächen verhärteter Kalkarenite fallen bei Niedrigwasser trocken und deuten durch Landschnecken und rötliche Verwitterungszonen auf ursprünglich terrestrische Sedimentationsbedingungen hin.

\section{Bildung und Alterstellung der Äolinite}

Für die Anlieferung des marin-bioklastischen Kalkmaterials der Äolinite kommen zwei Möglichkeiten in Betracht:

1. Das Ausblasungsgebiet war ein Strandsaum, der die Insel - ähnlich wie an der heutigen SE-Küste - umgab (relativer Meereshochstand). 
2. Das Ausblasungsgebiet war der zur Zeit glazialer Meeresspiegelabsenkung trocken gefallene Schelfbereich von Porto Santo.

Während die erste Möglichkeit nur wenig über die zeitliche Stellung der Äolinite innerhalb des Quartärs aussagt, schränkt die zweite den Zeitraum und die Bildungsumstände wesentlich ein.

Bei der e rsten Annahme muß man von der Vorstellung ausgehen, daß rings um die Insel auf die Küste gerichtete Strömungen vorhanden waren, die ständig bioklastisches Kalkmaterial heranführten. Dieser Vorstellung bietet sich aber heute kein Vergleich an. Schon auf Grund der Lagerungsverhältnisse der Älinite (Auflagerung auf Steilküste ohne Strandsaum, Abtauchen unter den Meeresspiegel) ist ersichtlich, daß die heutige Küste nicht als Modell für die Zeit der pleistozänen Dünenanwehung gelten kann. Auch der Sandstrand der SE-Küste, das Ausblasungsgebiet der rezenten Dünen, kann nicht als Beispiel herangezogen werden, da er lediglich ein Aufarbeitungsprodukt verfestigter Dünen ist, die heute längs dieser Küste unter den Meeresspiegel abtauchen. Eine nennenswerte Anlieferung bioklastischen Kalkmaterials an den heutigen Strand findet nicht statt.

Für die $\mathrm{z}$ weite Auffassung spricht, daß die Basis der an der E-Küste aufgeschlossenen Aolinite eine marine Strandterrasse ist, die zeitlich vermutlich dem mediterranen Tyrrhen III gleichzusetzen ist (vgl. VI). Die Äolinite wären hier demnach ins Würm-Glazial zu stellen. Auch das A b ta u chen der Aolinite unter den heutigen Meeresspiegel längs der SE-Küste spricht für einen tiefer gelegenen Meeresspiegel zum Zeitpunkt ihrer Bildung. Die Möglichkeit, daß tektonische Bewegungen dafür verantwortlich sind, läßt sich zwar nicht ausschließen, aber es gibt für solche Bewegungen keinerlei sichere Anhaltspunkte. Vulkanische Tätigkeit trat sowohl während als auch nach der Aolinitbildung nicht mehr auf.

Am überzeugendsten weist wohl die topographische Situation auf die zweite Auffassung hin. Der heutige Schelfbereich von Porto Santo bietet sich nämlich als Liefergebiet der fossilen Dünen zwanglos an (Abb. 1). Nach der Seekarte des Madeira-Archipels (1:150000) umschließt er mit einer Fläche von ca. $200 \mathrm{~km}^{2}$ (etwa das 4 fache der Insel) Porto Santo bis zu einer Tiefe von $100 \mathrm{~m}$ als eine einheitliche Plattform. Zwischen 100 und $200 \mathrm{~m}$ folgt ein scharfer Abbruch auf Tiefen bis zu $500 \mathrm{~m}$, und schon in $1 \mathrm{~km}$ Entferung vom Abbruch treten $\mathrm{z}$. T. Tiefen bis zu $1000 \mathrm{~m}$ auf. Mit $14 \mathrm{~km}$ erreicht die submarine Plattform vor der W-Küste ihren größten Abstand. Über ihr Oberflächenrelief erlaubt die Seekarte keine detaillierten Aussagen, doch scheinen im 50-60 m Niveau größere Verebnungsflächen vorzuliegen. Das weite Vorgreifen des Schelfes im W deutet an, daß sich die Insel einmal besonders in dieser Richtung erstreckt haben muß und auch vermutlich aus dieser Richtung her einer bevorzugten Abrasionswirkung des Meeres unterlag.

Die submarine Plattform muß man als bevorzugten Lebensraum mariner Kalkschaler und Sedimentationsraum biogener Skelettfragmente betrachten. Als rezente Beispiele können hierfür u. a. Schelfbereiche der südlichen USA, aus der Karibischen See und von Australien gelten, deren Sedimentbedeckung im wesentlichen aus biogenem Kalkmaterial besteht (Koldewijn 1958, Pilkey 1964, Emery 1966, Conolly \& v. D. Borch 1967). Rechnet man nun für die letzte Eiszeit mit einer Meeresspiegelabsenkung von ca. 90100 m (vgl. Flint 1957, Woldstedt 1969, Guilcher 1969 u. a.), so müssen über längere Zeiträume hinweg große Teile der Plattform um Porto Santo trockengefallen sein. Bei ausreichender Bedeckung mit bioklastischen Sedimenten und bei entsprechenden Windverhältnissen konnten sie so zum Ausblasungsgebiet der fossilen Dünen werden.

Die Aolinit-Vorkommen von Fon te de A reia unterstreichen diese Vorstellung besonders eindrucksvoll. Die hier durch das Einfallen der Schrägschichtung angezeigte 
Windrichtung deckt sich genau mit der größten Längserstreckung der dieser Küste vorgelagerten Plattform. Die Äolinite, die heute einer $100 \mathrm{~m}$ hohen Steilküste aufliegen, sind nur noch der Rest eines Dünenfeldes, das sich ehemals weiter nach NW erstreckte und inzwischen $\mathrm{zu}$ einem großen Teil der marinen Abrasion zum Opfer gefallen ist. Da man annehmen muß, daß die Küste einst flacher geböscht war, ist eine Aufwehung der Dünen bis zu der heutigen Höhe ohne weiteres vorstellbar (vgl. VIII).

Auch die übrigen Äolinitvorkommen im Küstenbereich der Insel stellen heute nur noch die Erosionsreste von Dünenkomplexen dar, die vormals seewärtig weiter a usgedehnt waren. Wie ihre Verteilung rings um die Insel beweist, war der äolische Transport nicht nur an eine einzige Windrichtung gebunden, sondern erfolgte an den verschiedenen Küsten jeweils durch aufs Land gerichtete Winde. Das jedoch von Fonte de Areia bis fast an die SE-Küste zu verfolgende, vorherrschend südöstliche Einfallen der Schrägschichtung läßt vermuten, daß die NW-Komponente unter den damaligen Windrichtungen stärker ausgeprägt war als unter dem heutigen NE-Passat-System.

Fast ausnahmslos werden pleistozäne Aolinite auch in a n de re n G e b i e t e n mit einem glazial-eustatischen Tiefstand des Meeres in Verbindung gebracht (z. B. Bermudas: Sayles 1931, Puerto Rico: Kaye 1959, Mittelmeerraum: Butzer \& Cuerda 1962, marokkanische Atlantikküste: G. Choubert 1961, Biberson 1961, Australien: Fairbridge \& Teichert 1953, Hawaii: Lum \& Stearns 1970). Auf den Bermudas jedoch wird neuerdings (entgegen SAYLES) eine andere Auffassung vertreten (Bretz 1960, MackenziE 1964, LAND et al. 1967): die dortigen Aolinite sollen in Zeiträumen interglazialer Meereshochstände, eingelagerte Böden während der glazialen Meerestiefstände gebildet worden sein.

BRETZ sowie LAND et al. begründen diese Aussage im wesentlichen folgendermaßen:

1. Verzahnungszonen zwischen Äoliniten und Strandsedimenten finden sich über dem heutigen Meeresspiegel.

2. Die Organismen, die das bioklastische Kalkmaterial lieferten, können nur auf einer ausgedehnten untermeerischen Plattform gelebt haben und nicht in einer schmalen Zone des äußersten Schelfes zur Zeit eines abgesenkten Meeresspiegels.

3. Rote Böden, die den Äoliniten eingelagert sind, tauchen unter den Meeresspiegel ab.

Alle drei Argumente sind nach unserer Meinung jedoch keineswegs zwingend:

1. Solche Verzahnungszonen über dem heutigen Meeresspiegel sind eigentlich immer zu erwarten, zumal wenn durch eine Transgression ältere Äolinite wieder aufgearbeitet wurden. Die Überlagerung von Strandbildungen durch Äolinite (s. BRETz, S. 1735) läßt sich aber einleuchtend doch nur durch "Regressionsdünen" erklären.

2. Die Vorstellung, daß durch eine Regression Schelfbereiche mit bereits vorhandener bioklastischer Sedimentbedeckung als Auswehungsgebiet frei wurden, besitzt zumindest eine ebenso große Wahrscheinlichkeit.

3. Bodenbildung und Dünenanwehung schließen sich zwar gegenseitig aus, aber das Abtauchen der Böden unter den heutigen Meeresspiegel spricht noch nicht für eine interglaziale Stellung der Äolinite. Ebenso können Stillstandsphasen während der Regression Unterbrechungen in der Dünenanwehung bedeutet haben und Anlaß für Bodenbildung gewesen sein.

Unsere kritischen Anmerkungen zu den Angaben von BRETz sowie LaND et. al. können die Auffassung dieser Autoren zwar nicht widerlegen, aber uns scheint, daß ihre Ablehnung der früheren SAYLEs'schen Auffassung nicht eindeutig genug begründet ist.

Für unsere Auffassung, daß die Äolinite auf Porto Santo zur Zeit eines glazial abgesenkten Meeresspiegels gebildet wurden, sind weiterhin C $\mathbf{1 4}$ - D a tier u n gen von Bedeutung, die wir dem II. Physikalischen Institut Heidelberg verdanken. Sie ergaben für Landschnecken aus den oberen Äoliniten von Fonte de Areia (Abb. 6a) ein Alter von $21570 \pm 350$ B.P. (H 3173-2437) und für Landschnecken aus den Gehängeschutteinlagerungen in den oberen Aoliniten von Porto dos Frades (Abb. 7b) ein Alter von 
$13.480 \pm 120$ B.P. (H 3711-2441), d. h. jüngeres W ü rm. Zu diesen Zeitpunkten kann man mit einer Meeresspiegelabsenkung von ca. 100 bzw. $40 \mathrm{~m}$ rechnen (zuletzt GuILCHER 1969).

Für die tieferen Äolinitabschnitte muß außer der vermuteten glazialen Zuordnung eine genauere zeitliche Einstufung noch offen bleiben. Auch die eingelagerten Böden bieten hier keinen geeigneten Ansatzpunkt, um zu entscheiden, ob die verschiedenen Abschnitte verschiedenen Glazialen oder vielleicht nur einem einzigen angehören. Die Böden begrenzen zwar Zeitabschnitte glazialer Dünenanwehung oder gehen ihr voraus, aber weder ihre Lagerungsverhältnisse noch ihre klimatische Aussagekraft sind vorerst geeignet, sie als interglaziale oder interstadiale Bildungen einzustufen.

\section{Bodenbildungen im Bereich der Äolinite}

B raunlehme

Braunlehme im Sinne von Kubiena (1953) kommen sowohl an der Basis der Aolinite (Abb. 6a, b) als auch zwischen schräggeschichteten Abschnitten vor (Abb. 6a, Horiz. 7; Abb. 6b, Horiz. 3).

Die Farbe der Braunlehme variiert - bei den basalen oft in Abhängigkeit von der Färbüng des vulkanischen Ausgangsgesteins - zwischen braunrot, ocker und graubraun. Im trockenen Zustand ist der Braunlehm fest, besitzt meistens ein säulig-prismatisches Gefüge und zeigt auf Bruchflächen einen wachsartigen Glanz. Sein Hohlraumvolumen ist nicht sehr groß und beschränkt sich fast nur auf kleine Wurzelkanäle, die vielfach mit Tonsubstanz wieder verfüllt sind. Der Tonanteil des Bodens liegt bei $90 \%$. Der Rest entfällt überwiegend auf nicht aufschlämmbare Tonaggregate sowie ferner auf einige Schwerminerale, Zeolithe und kleine Gesteinsbruchstücke. Bei Befeuchtung wird der Braunlehm hochplastisch und zerfließt leicht. Im allgemeinen ist die Bodensubstanz völlig kalkfrei. Nur auf Gefügeflächen befinden sich gelegentlich feine Kalktapeten, die auf deszendente Lösungen aus den darüber liegenden Äoliniten zurückzuführen sind. An der heutigen Oberfläche liegender Braunlehm ist meistens vererdet. Die Bodensubstanz ist dann ziemlich porös, kalkhaltig und hat weitgehend ihre Plastizität verloren.

Röntgenographisch ist trotz des Quellvermögens der Bodensubstanz Montmorillonit kaum nachweisbar. In der Regel ist nur ein schwacher und diffuser Reflex um $18 \AA$ sowie ein breiter, unregelmäßig begrenzter Illit-Reflex und ein schwacher Kaolinit-Reflex vorhanden. Der fehlende Nachweis von Montmorillonit ist nach Klages \& Southard (1968) vermutlich auch hier - infolge intensiver Verwitterung - auf den Aufbau äußerst unregelmäßiger, beugungsschwacher Wechsellagerungsstrukturen zurückzuführen.

Die Mächtigkeit der basalen Braunlehme schwankt wegen ihrer leichten Verschwemmbarkeit und des unausgeglichenen Untergrundreliefs ziemlich stark. Nicht umgelagert sind sie in einer Mächtigkeit bis zu $60 \mathrm{~cm}$ als tonige Verwitterungszone des vulkanischen Untergrundes nur an einzelnen Stellen im Tal des Rib. Cochino aufgeschlossen. Hierbei besteht zwischen den unverwitterten Vulkaniten und dem Braunlehm in Form zunehmender Vertonung ein gradueller Übergang. Als Bodensedimente und dann meist mit Geröllen und Landschnecken durchsetzt - erscheinen die Braunlehme als dichte, grüngraue Tone an der Basis der Äolinite von Fonte de Areia (Abb. 6a) in einer Mächtigkeit bis zu $10 \mathrm{~m}$ und im Mittelteil des gleichen Profils erneut als ein bis zu $5 \mathrm{~m}$ mächtiger Horizont. Die Muldenlage begünstigte hier offensichtlich die Zusammenschwemmung größerer Bodenmassen, wobei gestautes Grundwasser vermutlich die Reduktion der färbenden Eisenverbindungen bewirkte.

Die den Äliniten zwischengelagerten Braunlehmhorizonte in den Talprofilen des Rib. Salagado und des Rib. Cochino sind sicherlich keine autochthonen Böden. Stark wechselnde Mächtigkeiten $(0-2 \mathrm{~m})$, scharfe Liegend- und Hangendgrenzen und die häufige Durchmischung mit Landschneckengehäusen, Äolinitmaterial und Vulkanitgeröllen sprechen für umgelagertes Bodenmaterial, dessen Herkunftsgebiet in Bereichen zu suchen ist, in denen keine karbonatische Dünenbildung erfolgte. 
Eine genaue zeitliche Einstufung der Braunlehmbildung läßt sich noch nicht durchführen. Für die überwiegend autochthonen Braunlehme an der Basis der Äolinite ist nur eine relative Altersangabe möglich, und zwar: älter als die erste pleistozäne Dünenanwehung. Aus der Überlegung heraus, daß die Dünen zum Zeitpunkt eines glaziál abgesenkten Meeresspiegels angeweht wurden, ließe sich die Bildung der Braunlehme allenfalls noch auf ein wohl interglaziales Alter einengen. Die den Aoliniten eingelagerten Braunlehme lassen sich als Bodensedimente zeitlich überhaupt nicht fixieren. Sie können sowohl einer jüngeren Bodenbildung außerhalb des Verbreitungsbereiches der Äolinite entsprechen, als auch nur Erosionsmaterial der älteren Braunlehme darstellen. Die Aufschlußverhältnisse lassen hierüber keine Entscheidung zu.

\section{Rötliche Kalksandböden}

Neben den Braunlehmen treten in den Aoliniten noch karbonatische, rötlich-braun gefärbte Bodenhorizonte auf. Bei Fonte de Areia erscheinen diese Horizonte in mehrfacher Wiederholung (Abb. 6a, Horiz. 3, 5, 8, 10, 12) und gehören hier stets zu den flachlagernden Schichten, die das Gesamtprofil in drei große, schräggeschichtete Abschnitte gliedern. Ihre mehrfache Wiederholung zwischen zwei schräggeschichteten Abschnitten beruht hier auf wiederholter Einschwemmung von Bodenmaterial innerhalb der breiten Senke. Zu den Rändern der Depression hin verliert sich nämlich diese mehrfache Aufgliederung, und als Einzelhorizonte sind sie dann auch über größere Entferungen zu verfolgen.

In den bis $1 \mathrm{~m}$ mächtigen rötlichen Kalksandböden herrschen noch die Komponenten der Kalkarenite vor. Die Hauptmasse der Bodensubstanz entfällt als Skelettmaterial auf die detritischen Komponenten, und der Tonanteil stellt lediglich die Bindesubstanz zwischen den Einzelkörnern dar. Der gesamte nichtkarbonatische Anteil kann in diesen Horizonten im Vergleich zu den Äoliniten $(3 \%$ ) bis auf $20 \%$ ansteigen. Häufig ist eine reiche Landschneckenführung für die Böden besonders charakteristisch.

An ihrer Untergrenze gehen die rötlichen Kalksandhorizonte stets in Kalkzementtierungszonen über (Abb. 6a, Horiz. 9, 11), die als Ca-Horizonte des jeweiligen Bodenprofiles zu deuten sind. Stellenweise sind es sogar plattige Kalkkrustenlagen, die unter starker Auflockerung des Gefüges die rötlichen Horizonte begleiten. An mehreren Stellen (z. B. Rib. Cochino) sind die verschiedenen Aolinitabschnitte auch nur noch durch eine Kalkkrustenlage voneinander getrennt. Es ist möglich, daß hier ursprünglich vorhandenes Bodenmaterial bis auf die Unterkruste erodiert wurde.

Im Gegensatz zu den eingelagerten Braunlehmen stellen die den Äoliniten eingelagerten rötlichen Kalksandböden autochthone bis parautochthone Bildungen dar. Sie sind damit Zeitmarken einer Unterbrechung in der Dünenanwehung, verbunden mit einer Verwitterung des klastischen Kalkmaterials. Ihr Auftreten im NW-Teil der Insel erlaubt für diesen Raum eine Dreigliederung der Äolinite. Eine Zuordnung der übrigen Äolinitvorkommen der Insel $\mathrm{zu}$ diesem Gliederungsschema ist schwierig, da die Vorkommen entweder $\mathrm{zu}$ isoliert, zu geringmächtig oder ohne geeignete Bezugshorizonte sind. Außerdem scheint ein Teil der Äolinite der E-Küste unter dem heutigen Meeresspiegel zu liegen.

Zur Altersstellung der Böden können nur relative Angaben gemacht werden. So läßt sich für den oberen Boden aufgrund der erwähnten C14-Daten aus dem Profil von Fonte de Areia nur ein Mindestalter von $21570 \pm 350$ B. P. angeben.

\section{Bodenbildung im Hangenden der Aolinite}

Im Bereich des Rib. Cochino und des Rib. Salagado bildet ein lockerer rötlichbraunbis ockerfarbener, braunerdeartiger Boden als heutige Oberfläche den Abschluß der Äolinite (Abb. 6b, Horiz. 6). Seine Beschränkung auf diesen Raum beruht auf Zusammenspülung in den flachen Taldepressionen. Der Boden besitzt stellenweise als Skelett- 
anteil noch viel Karbonatmaterial der Äolinite, z. T. ist er jedoch auch fast gänzlich entkalkt. Zwischen Äolinite und Boden ist überall ein bis zu $50 \mathrm{~cm}$ starker Kalkkrustenhorizont eingelagert. An Hanglagen ist der Boden vollständig erodiert, so daß der harte Kalkkrustenpanzer hier den Abschluß bildet. Die Mächtigkeit des Bodens schwankt je nach Umfang der Zusammenspülung zwischen $0-2 \mathrm{~m}$.

Der Boden ist offensichtlich holozän, aber - wie die Verschwemmung zeigt - auch nicht ganz rezent. Vielleicht hängt seine Verschwemmung mit einer anthropogen bedingten Entwaldung nach Besiedlung der Insel seit dem 15. Jhd. zusammen. Eine solche Entwaldung mag auch der Grund sein, daß große Flächen von Porto Santo heute überhaupt keine Bodenbedeckung besitzen. Spärliche Vegetation fördert fast überall Abspülung und erosive Zerschneidung. Für Anbau genutzte Flächen führen meist nur eine flachgründige Bodenkrume, die durch Steinwälle vor Wind- und Wassererosion geschützt werden muß.

\section{Kolluvial-Ablagerungen}

Unter Kolluvium ist hier entsprechend dem Gebrauch im englisch-sprachigen Schriftum (vgl. Fairbridge in „Encycl. of Geomorph.“, 1968, S. 161) Schutt- und anderes Gesteinsmaterial verstanden, das durch Schwerkraft, Bodenfließen, Abspülung u. ä. meist nur geringfügig verlagert ist.

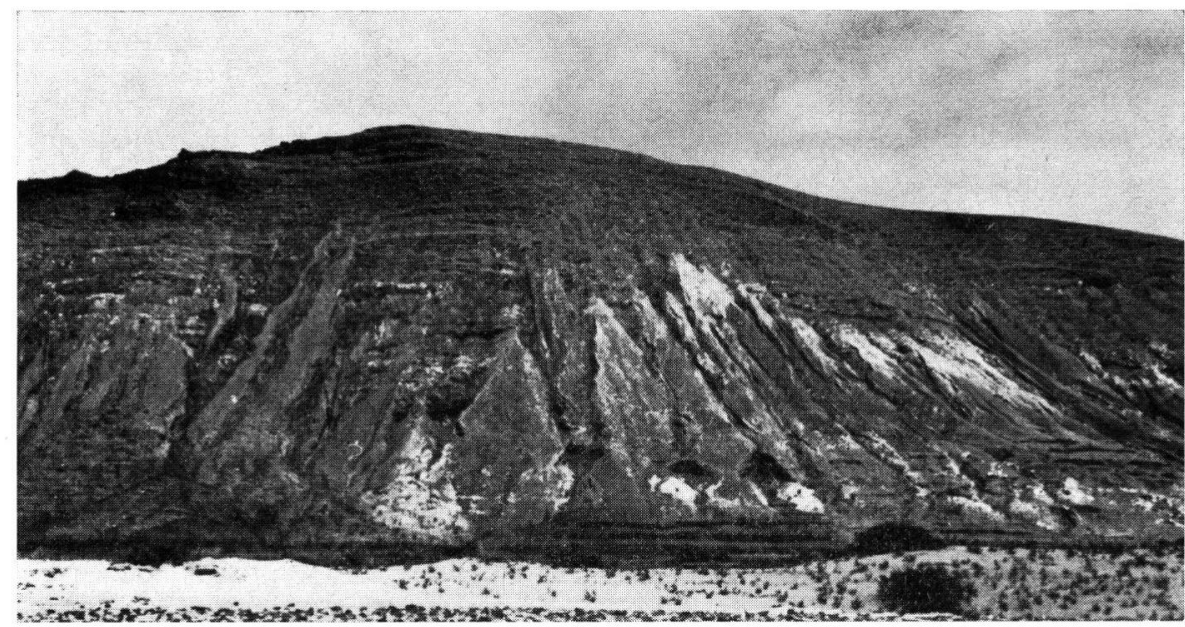

Abb. 9. Der steile Hang aus tertiären Vulkaniten (N Ponta da Calheta) ist mit Gehängeschutt verkleidet, der oberflächlich kalkzementiert, stellenweise mit Aolinit verzahnt und von zahlreichen Erosionsrinnen zerschnitten ist. Vorn z. T. bewachsene Dünen.

Auf Porto Santo gehört rot-brauner Verwitterungsschutt der vulkanischen Gesteine als Gehängeschutt (Abb. 9 u. 10a) oder Ausfüllung flacher Depressionen (Abb. 2 u. 10b) neben den Äoliniten zu den charakteristischen Bildungen des Quartärs. Im SW der Insel tritt er in größerer Verbreitung zwischen den Flanken von Pico Ana Fereira und dem Höhenrücken des Espigao auf und zieht von hier entlang den östlichen Berghängen bis zu Cabeço do Zimbralinho an der S-Spitze der Insel. NE vom Ort Porto Santo begleitet er, unmittelbar gegen das Meer grenzend, die Berghänge der E-Küste.

Eine intensive, schluchtartige Zerschneidung hat die Kolluvialsedimente in einer manchmal bad-land ähnlichen Landschaft überall gut aufgeschlossen. Ihre größte Mächtigkeit dürfte bei ca. $30 \mathrm{~m}$ liegen. Genauere Angaben sind schwierig, da die Einschnitte den vulkanischen Untergrund oft gar nicht erreichen. Die starke erosive Zerschneidung 


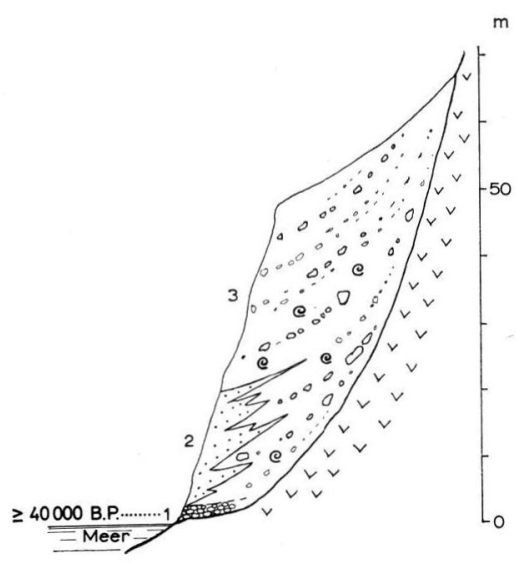

(a)

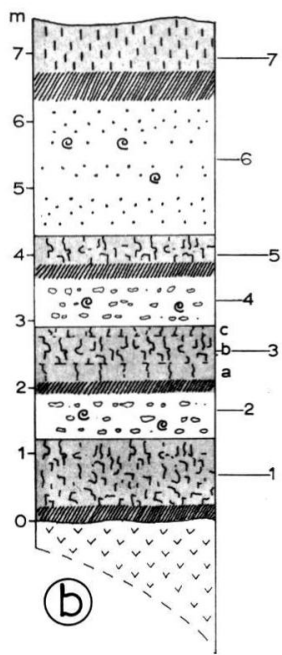

Abb. 10. Kolluvium-Aolinit-Profile. a. SE-Küste zwischen dem O'rt Porto Santo und der E-Spitze der Insel; b. Oberer Rib. Salagado. (Legende Abb. 5.)

der Schuttmassen demonstriert zugleich ihre hohe Standfestigkeit. Nur in den niederschlagsreicheren Jahreszeiten findet in den zahllosen Wasserrissen ein geringer Materialtransport statt. Der Gehängeschutt verkleidet immer schleppenartig das Relief des vulkanischen Untergrundes. Durch den Wechsel groben und feinen Materials sind die Sedimente meistens etwas, stellenweise auch gut geschichtet, aber durchweg schlecht oder überhaupt nicht sortiert. Je nach Art des vulkanischen Ausgangsgesteins bestehen sie aus Grobschuttbildungen mit Blöcken bis zu $2 \mathrm{~m}$ Durchmesser oder aus überwiegend tonigsandigem Material; stellenweise ist auch umgelagertes Bodenmaterial miteinbezogen (Abb. 10b). Mehrfach sind in die Schuttsedimente durchhaltende Kalkkrustenhorizonte eingelagert, deren Bildung vielleicht an pedogene $\mathrm{Ca}-Z$ Zementierungen geknüpt war.

$\mathrm{L}$ andschnecken kommen in den kolluvialen Sedimenten wie auch in den Aoliniten und den rötlichen Kalksandböden stellenweise dicht $\mathrm{geh}$ ä uft vor. Zum größten Teil ist das wohl auf Anreicherung durch Zusammenspülung oder durch Wind zurückzuführen. Aber in manchen Fällen dürfte es sich einfach um herabgefallene und $\mathrm{kaum} \mathrm{umgelagerte} \mathrm{Ge}$ $\mathrm{h} \ddot{\mathrm{a}} \mathrm{use}$ handeln. Die heutigen Verhältnisse geben eine gute Vorstellung davon, wie leicht es zu solchen Anhäufungen kommen kann: Grashalme, Kräuter, Astchen von Tamarisken usw., ja, selbst Leitungsmasten sind manchmal von daran anhaftenden lebenden Schnecken geradezu gepanzert. Die abgestorbenen Gehäuse liegen dann später zu Hunderten am Boden - es bedarf weder des fließenden Wassers noch des Windes, um nach ihrer Eindeckung "Schneckennester" zu erzeugen. Man möchte annehmen, daß auch manche "Schneckennester" i m kaltzeitlichen $L \ddot{0} ß$ auf solche einfache Weise zu erklären sind.

Für die Altersstellung und die Bildungsbedingungen der Kolluvialablagerungen sind Aufschlüsse entlang der E-Küste zwischen dem Ort Porto Santo und dem Straßentunnel vor der E-Spitze der Insel wichtig. Die Profile (Abb.10a) zeigen hier an der Basis in $0-1 \mathrm{~m}$ über NN ein fossilführendes Brandungskonglomerat (1), das zu der einzigen pleistozänen Strandterrasse gehört, die auf Porto Santo überhaupt ausgebildet ist (vgl. VI). In dieses marine Konglomerat ist an verschiedenen Stellen der rotbraune Gehängeschutt an seiner Basis miteinbezogen. Die Gerölle sind dann deutlich besser gerundet, und in der kalkig-sandigen Matrix stecken zahlreiche Schalenreste mariner Mollusken.

Úber dem Konglomerat folgt in der Regel eine bis zu $10 \mathrm{~m}$ mächtige Verzahnungszone zwischen äolischen Kalkareniten und Gehängeschutt (2), die dann nach oben zu meistens in reine Gehängeschuttbildungen übergeht (3). Stellenweise treten auch die 
Äolinite mehr in den Vordergrund, aber sie sind immer von groben Gerölleinlagerungen durchsetzt.

Die Verzahnung zwischen Gehängeschutt und Äoliniten beweist, daß D ü n e nanwehung und Hangschuttbildung hier im gleichen Zeitabschnitt erfolgten. Die Hangschuttbildung ist damit ebenfalls in den Zeitraum eines glazial abgesenkten Meeresspiegels zu stellen. Dem widerspricht auch nicht, daß ein Teil der Schuttsedimente an der Basis marin aufgearbeitet ist. Da der marine Horizont mit einiger Wahrscheinlichkeit zeitlich in das ausklingende letzte Interglazial (Tyrrhen III) $\mathrm{zu}$ stellen ist (vgl. VI), wäre die Hauptmasse der auf ihn folgenden Hangsedimente mit den eingelagerten Aoliniten in das Würm-Glazial zu stellen. Das erwähnte C14-Alter von 13480 B. P. für Landschnecken aus den Hangschutteinlagerungen in den oberen Äoliniten von Porto dos Frades stimmt mit dieser Annahme sehr gut überein. Über die zeitliche Stellung der übrigen Gehängeschuttbildungen innerhalb des Pleistozäns können noch keine sicheren Aussagen gemacht werden. Die auch hier zu beobachtende Verzahnung mit Äoliniten läßt nur vermuten, daß es ebenfalls kaltzeitliche Bildungen sind. Aus dem Mediterranraum beschreibt BUTZER (1962) ebenfalls rote Kolluvialsedimente, die sich mit würmzeitlichen „Regressionsdünen“ verzahnen.

Die Entstehung der Kolluvialablagerungen muß man sich aufgrund des Sedimentbildes als flächenhaften Massentransport über relativ geringe Entfernungen vorstellen. Kurzfristige Niederschläge mit hohem Oberflächenabfluß dürften dabei für die Verfrachtung besonders wirksam gewesen sein. Im Erscheinungsbild ähnliche pleistozäne Ablagerungen beschreiben Wiche (1961), Butzer \& Cuerda (1962), Butzer (1964) und Rohdenburg \& Sabelberg (1964) aus dem südlichen Mediterranraum.

\section{Vorläufige Liste pleistozäner Landschnecken von Porto Santo}

Zusammengestellt von F. STrauch

In Klammern: bisher nachgewiesene zeitliche und regionale Verbreitung nach Mandahl-Barth (1943) und A. Zilch (1959-60)

A, B, G: Vorkommen auf Porto Santo auf Grund unserer Aufsammlungen

( $\mathrm{A}=$ Aolinit, $\mathrm{B}=$ Kalksandboden, $\mathrm{G}=$ Gehängeschutt)

Geomitra (Geomitra) coronata (Deshayes) (pleist.-rez., Madeira) A, B, G

Heterostoma paupercula (LowE) (pleist.-rez., Porto Santo, selten Madeira, Kanaren, Azoren) A, B Spirorbula cf. obtecta (LowE) (pleist.-rez., Porto Santo, Madeira) Ä, B, G

Helicomela bowdichiana (FÉrussaC) (fossil nur von Porto Santo u. Madeira; Gattung im Paläogen in ganz Mittel- und Westeuropa, rez. nur Madeira) A, G

Helicomela sp. G

Ochthephila (Caseolus) compacta portosanctana (Lowe) (typische rez. Art nur auf Madeira) A, B, G

Ochthephila (Caseolus) cf. commixta (LowE) $\mathrm{A}, \mathrm{B}$

Ochthephila (Caseolus) sp. A

Discula (Discula) bulweri (Wood) ? (rez. Art nur Porto Santo, Gattung nur Madeira) A, B, G Discula (Discula) sp. A, B

Discula (Tectula) tectiformis ludovici (Albers) (nur Pleistozän von Porto Santo, Untergattung nur Porto Santo ?) Ä, B

Psendocampylaea lowei (FÉRussac) (Gattung pleist.-rez. nur Porto Santo und benachbarte Inseln) B, G

Leptaxis (Leptaxis) chrysomela (PFeIfrer) (nur Pleistozän von Porto Santo) A, G

Leptaxis (Katostoma) psammophora (LowE) (nur Pleistozän von Porto Santo) G

Leptaxis sp. G

Theba pisana (Müller) (rez. mediterrane Art) G

Helix (Idiomela) subplicata Sowerby (Untergattung rez. nur von Porto Santo; pleist.-rez. Porto Santo) A, B, G

Amphorella (Fusillus) oryza (Lowe) A 


\section{Pleistozäne Strandterrasse}

Im Gegensatz zu anderen atlantischen Inseln (z. B. Gran Canaria, KLUG 1968) ist auf Porto Santo nur e ine Strandterrasse nachzuweisen. Sie ist als Brandungskonglomerat ausgebildet und tritt unmittelbar an der Küste als Basis der Äolinite von Porto dos Frades (Abb. 7) und an der Basis des Gehängeschuttes östlich von Porto Santo (Abb. 10a) sowie in mehreren Talmündungen (bis zu $70 \mathrm{~m}$ landeinwärts) an der E- und SE-Küste auf (Rib. do Calhau, Rib. da Vigia, Rib. do Atalho, Rib. Cochino, s. auch Abb. 1).

Die Konglomerate liegen $\mathrm{zw}$ is che $\mathrm{n}$ und $+3 \mathrm{~m} \mathrm{NN}$ und werden maximal $2 \mathrm{~m}$ mächtig. Seewärts liegen sie stellenweise auf Kalkareniten, die unter den Meeresspiegel eintauchen. Die Gerölle der Brandungskonglomerate bestehen überwiegend aus Gesteinen des vulkanischen Untergrundes, nur vereinzelt kommen auch verhärtete Kalkarenitgerölle vor. Sie erreichen Durchmesser bis $\mathrm{zu} 30 \mathrm{~cm}$ und stecken in einer unterschiedlich verfestigten Kalksandmatrix. Nur im Gezeitenbereich sind die Konglomerate durchweg stark verhärtet. Durch den Wechsel groben und feinen Materials ist häufig eine Schichtung vorhanden, die mit $8-10^{\circ}$ zum Meer hin einfällt.

Das auffälligste Kennzeichen der Brandungskonglomerate ist ihre reiche Fossil-

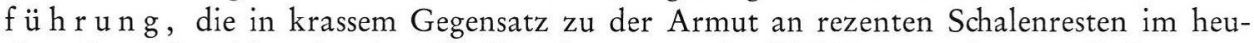
tigen Strandbereich steht. Aus den Konglomeraten der SE-Küste wurden von F. STRAUCH folgende Formen bestimmt:

Patella (P.) caerula L.

Patella (P.) Insitanica GMELIN

Gibbula sp.

Turbo rugosus $\mathrm{L}$.

Mamilla lactea (GuILDing)

Callista chione (L.)

C 14 - D a t i e r ungen von Patella-Schalen aus der Strandterrasse an der Mündung der Rib.da Vigia ergaben ein Mindestalter von 40000 B.P. Die Einzelwerte sind: $\geqq 41500$ (H 3174-2438), $\geqq 39500$ (H 3175-2493) und $\geqq 430000$ (H 3176-2440). Nach diesen Datierungen und in Verbindung mit der Höhenlage sind die marinen Konglomerate am ehesten mit der Tyr rhen I I I-S t u fe des Mediterranraumes oder der Ouljan-Stufe Marokkos vergleichbar, für die Stearns \& Thurber (1965) auf Grund von Th230 / U234-Datierungen ein Alter zwischen 75000 und 90000 B. P. annehmen. ${ }^{4}$ )

Höhere Strandterrassen haben wir auf Porto Santo nicht gefunden. Es ist aber möglich, daß solche vorhanden waren, jedoch der Erosion zum Opfer fielen. Dies gilt besonders für den Raum NE von Porto Santo mit seinen auffallenden Verebnungen in den vulkanischen Gesteinen im 30-70 m Niveau. Durch denudative Hangabtragung, die hier sicherlich als entscheidender Faktor der morphologischen Prägung infrage kommt, können höher gelegene Strandsedimente leicht erodiert worden sein.

\section{Talbildung}

Sowohl die Äolinite als auch die Kolluvialsedimente füllen z. T. flache Drepressionen aus, die breiten Talböden entsprechen. KLUg (1968) hat ähnliche Täler auf den Kanaren als Kehl- und Muldentäler bezeichnet und ihre Bildung in ein jungtertiäres „wechselfeuchtes tropisches bis subtropisches Klima“" und in altpleistozäne Pluvialzeiten verlegt. In diese alten flachen Täler sind dort junge Kerbtäler eingeschnitten.

4) Beide Autoren lassen die Frage, ob diese Terrasse in das ausklingende letzte Interglazial zu stellen ist oder ob sie ein eigenständiges Interstadial innerhalb des Würm-Glazials darstellt, bewußt offen. Beide Auffassungen werden vertreten (s. Stearns \& Thurber 1965). 
Auch auf Porto Santo lassen sich $\mathrm{zw}$ e i Talgenerationen unterscheiden: die oben erwähnten flachen Depressionen und die ganz jungen, oft schluchtartigen Täler (Abb. 2). Die letzteren erodieren z. T. würmzeitliche Schichten, gehören also ins Würm oder Postglazial. Über die Altersstellung der älteren Talformen lassen sich noch keine bestimmten Aussagen machen. Ihr Alter läßt sich zunächst nur mit „älter als die erste kaltzeitliche Dünenanwehung und jünger als Miozän“ begrenzen.

\section{Zur Enstehung der Steilküste}

Die Steilküste von Porto Santo ist ju ng: die mächtigen, schleppenartig herabziehenden Gehängeschuttmassen werden an der SE-Küste abrupt abgeschnitten; die Aufwehung der Aolinite bei Fonte de Areia durch NW-Winde, $70 \mathrm{~m}$ über dem Meer, ist bei der heutigen Steilküste nicht vorstellbar. Da alle Anzeichen für tektonische Abbrüche fehlen, kann man nur rückschreitende $\mathrm{B}$ randungserosion als Ursache annehmen. Wir schließen uns den entsprechenden Ausführungen Schmincke's (1968) für Gran Canaria durchaus an. Der von Schmincke mit herangezogene Schelf ist bei Porto Santo ebenso schön entwickelt wie bei dieser Kanaren-Insel. Doch sollte man vielleicht nicht zu viel aus der Kongruenz von Windrichtung und Steilküste herauslesen; wahrscheinlich ist das (von Schmincke schon erwähnte) texturelle Gefüge der Schichten, die die Küste aufbauen (flache Lagerung mit steilen Klüften) noch wichtiger. Die Steilküste von Porto Santo ist nämlich sowohl nach $\mathrm{N}$ als nach $\mathrm{S}$, W und $\mathrm{E}$ exponiert, also nur z. T. im Einklang mit den herrschenden Winden. Noch mehr gilt diese Beobachtung übrigens für Madeira.

Uber die Geschwindigkeit der Brandungserosion lassen sich bei Fonte de Areia einige Hinweise gewinnen. Die Dünenbildung setzt dort eine flach ansteigende NW-Küste voraus. Noch vor 21000 Jahren muß ein solcher flacher Hang vorhanden gewesen sein und Sandtransport hangaufwärts ermöglicht haben. Welche H a n g neigungen dabei noch überwunden werden, zeigt u. a. die Kap-Halbinsel südlich von Kapstadt, besonders schön bei Hout Bay. Die Dünen erreichen dort nach MABвUT"r (1952) noch den $150 \mathrm{~m}$ hohen Paß zwischen Little Lions Head und Karbonkelberg, $2,5 \mathrm{~km}$ von Hout Bay entfernt, d. h. bei einer durchschnittlichen Hangneigung von ungefähr $3^{\circ}$. Das ist nicht unbedingt ein Maximalwert für Dünentransport, aber wahrscheinlich schon ein relativ hoher Wert, obgleich einzelne Gerölle bei Sturm noch bei erheblich größerer Neigung aufwärts gerollt werden (vgl. u. a. die Tabelle nach Grove \& Sparks in Schwarzbach 1964, S. 258). Für Fonte de Areia würde sich bei $3^{\circ}$ eine Entfernung der Küste von nur $1400 \mathrm{~m}$ ergeben (vgl. das Profil in Abb. 1). Bei der großen Breite des Schelfes fällt das kaum ins Gewicht. Die Tiefe des Schelfes beträgt dort etwa $30 \mathrm{~m}$. Der Meeresspiegel erreichte diese Stelle nach der letzten glazialen Absenkung vor schätzungsweise 12000 Jahren (vgl. Fairbridge 1968, S. 529). Wenn um diese Zeit die Rückverlegung der Küste begann, ergibt sich ein Durch sch nit t swert von $1400 \mathrm{~m} /$ $12000 \mathrm{a}=12 \mathrm{~cm} / \mathrm{a}$. Das wäre ein relativ hoher Wert für eine Felsküste und würde den Verhältnissen an Kliffküsten mit wenig verfestigten Gesteinen nahekommen. Aber der vulkanische Sockel von Porto Santo besteht aus stark geklüfteten und z. T. zersetzten, abtragungsgünstigen Gesteinen, und ein solcher Durchschnittswert erscheint deshalb nicht zu hoch.

\section{Zur quartären Klimaentwicklung auf Porto Santo}

Ein Ziel unserer Untersuchungen war es, Anhaltspunkte für die quartäre Klimaentwicklung im mittleren Atlantik zu gewinnen. Einige wichtige paläoklimatologische Schlußfolgerungen lassen sich ziehen. Manche Einzelheiten bleiben freilich noch unklar, 
und besonders die chronologische Zuordnung der Klimaphasen können wir nur teilweise durchführen. Zu einem vollständigen Bilde wäre es notwendig, die Arbeiten auf ein größeres Gebiet auszudehnen und andere Inseln in die Betrachtungen mit einzubeziehen.

Uber das heutige Klima von Porto Santo orientiert das Diagramm (Abb. 1): Jahresmittel der Temperatur $19^{\circ}$ (Januar $16^{\circ}$, September $23^{\circ}$ ), Niederschlag $350 \mathrm{~mm}$ mit Maximum in den Monaten Oktober-März.

\section{Glazialzeitliches Klima}

Der wichtigste Ausgangspunkt für die Rekonstruktion der quartären Klimaverhältnisse sind die Äolinite. Ihre Verknüpfung mit der eustatischen Meeresspiegel-Absenkung bedeutet, daß die Äolinite (und ebenso das mit ihnen verzahnte Kolluvium) kaltzeitlicher Entstehung sind. Wie groß die Temperatur-Absenkung war, läßt sich auf Porto Santo nicht bestimmen. Man darf allgemein nach den $\mathrm{O}^{18} / \mathrm{O}^{16-B e-}$ stimmungen von EmILIANI u. a. wohl mit ungefähr $5^{\circ}$ rechnen.

Sehr wichtig ist die Frage nach den glazialzeitlichen Niederschlägen. Für die Anwehung der Dünen und ihre Ausbreitung über die Insel möchte man rela t iv trockenes Klima voraussetzen, vielleicht noch trockener als heute, mit lückenhafter oder z. T. sogar fehlender Vegetation. Das würde dann auch für die Bildung der gleichalten kolluvialen Sedimente gelten. Periodische jahreszeitliche Niederschläge sorgten für deren kurzräumige Verfrachtung; eine dichte Pflanzendecke kann nicht existiert haben.

Das über große Flächen der Insel vorherrschend südöstliche Einfallen der Dünenschichtung deutet darauf hin, daß anstelle der heutigen NE-Komponente in der W in drichtung die NW-Komponente vorherrschte. Das würde der allgemeinen Vorstellung entsprechen, daß die planetarischen Windgürtel während der Glazialzeiten äquatorwärts verschoben waren und Porto Santo aus dem Passat- in den Westwindgürtel gerückt war.

Trockenes Klima im Glazial dieser Breiten entspricht nicht der herkömmlichen „klassischen“ Gleichsetzung von Glazial und „Pluvi a l“. Aber dieses einfache Schema hat sich inzwischen mehrfach als i $\mathrm{r} t \ddot{u} \mathrm{mli} \mathrm{ch}$ erwiesen, am meisten am äquatorwärtigen Rand der subtropischen Trockenzone (schon Balout 1952, Fairbridge 1965, zuletzt mit Damuth 1970, Galloway 1965, Van Zinderen Bakker 1966 u. a.). Doch auch im Mediterrangebiet neigen manche Forscher jetzt dazu, die glazialen Perioden für relativ trocken zu halten und aufgrund einer „engen Verknüpfung von Lößanwehung und starken Abspülvorgängen... Phasen starker Hangformung... mit vegetationsarmen Trokkenphasen zu korrelieren und nicht mit Feuchtphasen" (so Rohdenburg \& Sabelberg 1969b; vgl. auch BrunNacker \& LožEK 1969, Frenzel 1968 u. a.). Gerade mit solchen Vorstellungen aus dem Mittelmeerraum ließe sich auch ein relativ trockenes Glazialklima auf Porto Santo gut vereinbaren.

Die klimatische Aussagekraft der in Verbindung mit den Äoliniten auftretenden Böden ist nicht eindeutig. Lediglich für die b a s a le n autochthonen Braunlehme muß man relativ feucht-klimatische Verhältnisse annehmen. Für den westlichen Mediterranraum konnten Rohdenburg \& SAbelberg nachweisen, daß solche Böden keineswegs tropische Tertiärrelikte darstellen müssen, sondern auch während interglazialer Feuchtphasen des Pleistozäns gebildet wurden. Ein pleistozänes Alter der basalen Braunlehme ist auch für Porto Santo wahrscheinlich. Die den Äoliniten e ingelage rten Braunlehme lassen sich als Bodensedimente klimatisch nicht interpretieren. Es ist nicht mit Sicherheit nachzuweisen, daß ihre Einschwemmung zeitlich mit einer Braunlehmbildung außerhalb des Verbreitungsbereiches der Dünen einhergeht. 
Die rötlichen Kalksandböden innerhalb der Älinite stellen sicherlich keine sehr verwitterungsintensiven Bildungen dar. Im Vergleich zu den Braunlehmen kann man sie wohl kaum als klimatypisch ansehen, sondern lediglich als Zeitmarken einer Unterbrechung der glazialen Dünenanwehung.

\section{Eine mögliche Alternative für Deutung der Niederschlagsverhältnisse im Glazial}

Obgleich wir die eben gegebene Deutung von relativ trockenen Glazialzeiten für die wahrscheinlichere halten, möchten wir doch bezüglich der Äolinite auf eine grundsätzlich andere Möglichkeit hinweisen. Die Dünenbildung wurde ja dadurch veranlaßt, daß de r S chelf trokkenfiel. Am Rande der Insel tauchte also dann sozusagen eine a usgedehnte temporäre Wüste auf. Vegetationsloser Sand aber bedarf keines hocha riden Klimas, um vom Winde transportiert zu werden. Das Beispiel der großen Wanderdünen auf der Kurischen Nehrung in Ostpreußen - um nur dieses zu nennen - beweist, wie selbst im kühl-feuchten Klima Mitteleuropas Sand in großem Maßstab wandert. (Die verstärkte Wanderung an der Kurischen Nehrung in der Hälfte des 18. Jhd. wird auf Abholzung zurückgeführt.)

\section{R ückblick}

Die postvulkanischen Sedimente von Porto Santo sind im wesentlichen ins Pleistozän zu stellen. Alter als die älteste Dünenanwehung ist jedoch eine intensive Verwitterung und Abtragung des vulkanischen Sockels, die sich zeitlich nur mit „jünger als Miozän und älter als die tiefsten Äolinite“ begrenzen läßt. Zeugen dieser Vorgänge sind flächenhaft eingeebnete Vulkanite sowie autochthone und umgelagerte Braunlehme.

Innerhalb des Pleistozäns kam es dann kaltzeitlich (d. h. bei niedrigeren Temperaturen als heute) unter relativ trockenklimatischen Verhältnissen und in Verbindung mit einer Absenkung des Meeresspiegels zur Ablagerung von bioklastischen Dünen und von Kolluvialsedimenten. Die Dünenbildung wurde mehrfach durch Zeiträume unterbrochen, in denen die rötlichen Kalksandböden entstanden.

Die C14-Datierungen machen wenigstens für einzelne Abschnitte wahrscheinlich, daß sie ins W ü r m zu stellen sind. Ebenso scheint die marine Terrasse in $1-3 \mathrm{~m}$ über NN in das Tyrrhen III, d. h. in das letzte Interglazia l, zu gehören. Ob diese zeitliche Einordnung in das Würm bzw. Eem für alle quartären Bildungen gilt, oder ob diese sich auch auf das Prä-Eem erstrecken, läßt sich noch nicht sagen.

D a n k. Die Reise nach Porto Santo im Jahre 1968 wurde durch eine Beihilfe der Deutschen Forschungsgemeinschaft ermöglicht. Für die Reise von J. LIETZ 1969 stellte die Universität Köln einen Beitrag zur Verfügung. Für die wichtigen C14-Datierungen sind wir Prof. Dr. K. O. Münnich und Dipl.-Phys. D. Berdau (II. Physik. Institut Heidelberg), für die Fossilbestimmungen Dr. F. Strauch (Köln), für bodenkundliche Diskussionen Prof. K. Brunnacker (Köln), für die Durchsicht von Teilen des Manuskriptes Dr. P. Rothe (Heidelberg) zu Dank verpflichtet. Bei den Zeichnungen half uns Dr. G. Schultz. Dr. F. T. Mackenzie verdankt der ältere Verf. (M. S.) instruktive Führungen auf Bermuda.

\section{$\mathrm{Sch}$ riften}

Balout, A.: Pluviaux interglaciaires et préhistoire Saharienne. - Trav. Inst. Rech. Sahar. 8 , 9-19, Alger 1952.

Biberson, P.: L'évolution du Paléolithique marocain dans le cadre du Pléistocène atlantique. Quaternaria 6, 177-205, 1961.

Bretz, J. H.: Bermuda: A partially drowned, late mature Pleistocene karst. - Geol. Soc. Am. Bull. 71, 1729-1754, 1960.

Brunnacker, K., Altemüller, H.-J. \& Beug, H.-J.: Das Profil von Kitros in Nord-Griechenland als Typusprofil einer nordmediterranen Lößprovinz. - Eiszeitalter u. Gegenwart, 20, 90-110, 1969.

BrunNaCKer, K. \& LožEK, V.: Löß-Vorkommen in Südostspanien. - Z. Geomorph., 13, 297316, 1969. 
Butzer, K. W.: Environment and Archeology - an introduction to Pleistocene geography. 524 S., Chicago 1964.

- : Mediterranean area: Quaternary history. - Encycl. Oceanogr. (ed. R. W. Fairbridge), 485-490, New York 1966.

Butzer, K. W. \& CUerda, J.: Coastal stratigraphy of southern Mallorca and its implication for the Pleistocene chronology of the Mediterranean Sea. - J. Geol., 70, 398-416, 1962.

Choubert, G.: Réflexion sur les parallélismes probables des formations quaternaires atlantiques du Maroc avec celles de la Méditerranée. - Quaternaria, 6, 137-175, 1961.

Conolly, J. R. \& Borch, C. C. v. d.: Sedimentation and physiography of the sea floor south of Australia. - Sed. Geol., 1, 181-220, 1967.

Damuth, J. E. \& Fairbridge, R. W.: Equatorial Atlantic deep-sea arcosic sands and ice-age aridity in tropical South America. - Geol. Soc. Am. Bull., 81, 189-206, 1970.

Emeri, K. O.: Atlantic continental shelf and slope of the United States - geologic background. - Geol. Surv. Prof. Pap., 529 A, 1-23, Wash. 1966.

Fairbridge, R. W.: Eiszeitklima in Nordafrika. - Geol. Rdsch., 54, 399-414, 1965.

- : Carbonate rocks and paleoclimatology in the biochemical history of the earth. - Developments in Sedimentology, 9 A (ed. G. V. Chilingar et al.), 399-432, Amsterdam 1967.

- : The Encyclopedia of Geomorphology (ed.) - New York 1968.

Fairbridge, R. W. \& Teichert, C.: Soil horizons and marine bands in the coastal limestones of western Australia. - Roy. Soc. N. S. Wales J. Proc., 86, 68-87, 1953.

Flint, R. F.: Glacial and Pleistocene Geology. - 533 S., New York 1957.

FrenZEL, B.: Klimaschwankungen des Eiszeitalters. - 291 S., Braunschweig 1967.

Galloway, R. W.: A note on world precipitation during the last glaciation. - Eiszeitalter u. Gegenwart, 16, 76-77, Ohringen 1965.

Guilcher, A.: Pleistocene and Holocene sea-level changes. - Earth Sci. Rev., 5, 69-97, 1969.

Hartung, G.: Geologische Beschreibung der Inseln Madeira und Porto Santo. - 298 S., Leipzig 1864.

Kaye, C. A.: Shoreline features and Quaternary shoreline changes Puerto Rico. - Geol. Surv. Prof. Paper, 317 B, 49-138, 1959.

Klages, M. G. \& Southard, A. R.: Weathering of montmorillonite during formation of a solodic soil and associated soils. - Soil. Sci., 106, 363-368, 1968.

KLuG, H.: Morphologische Studien auf den Kanarischen Inseln. - Schrift. Geogr. Inst. Univ. Kiel, 24, 3, 1-184, 1968.

Koldewijn, B. W.: Sediments of the Paria-Trinidad-Shelf. - Publ. Fys. - Geogr. Labor Amsterdam, 1, 1-109, 1958.

KrejCi-Graf, K.: Vertikal-Bewegungen der Makaronesen. - Geol. Rdsch., 51, 73-122, 1951.

- : Zur Geologie der Makaronesen: 4. Krustenkalke. - Z. deutsch. geol. Ges., 112, 36-61, 1960.

- : Vulkaninseln und Inselvulkane; 4. Porto Santo. - Natur u. Volk, 91, 33-38, 1961.

- : Zur Geologie der Makaronesen: 5. „Versteinerte Büsche“ als klimabedingte Bildungen. N. Jb. Geol. Paläont. Abh., 113, 1-22, 1961.

- : Zur Geologie der Makaronesen: 8. Die mittelatlantischen Vulkaninseln. - Mitt. Geol. Ges. Wien, 57, 401-431, 1964.

Kubiena, W. L.: Bestimmungsbuch und Systematik der Böden Europas. - 392 S., Stuttgart 1953.

Land, L. S., Mackenzie, F. T., Gould, S. J.: Pleistocene history of Bermuda. - Geol. Soc. Am. Bull., 78, 993-1006, 1967.

Lietz, J. \& Schwarzbach, M.: Neue Fundpunkte von marinem Tertiär auf der Atlantik-Insel Porto Santo (Madeira-Archipel). - N. Jb. Geol. Paläont. Mh., H. 5, 270-282, 1970.

Lum, D. \& Stearns, H. T.: Pleistocene stratigraphy and eustatic history based on cores at Waimanalo, Oahu, Hawaii. - Geol. Soc. Am. Bull., 81, 1-16, 1970.

Mabbutr, J. A.: The physical landscape. - The Cape Peninsula (ed. J. A. Mabbutt), 13-32, Cape Town 1952.

Mackenzie, F. T.: Bermuda Pleistocene eolianites and paleowinds. - Sedimentology, 3, 51-64, 1964.

Mandahl-Barth, G.: Systematische Untersuchungen über die Heliciden-Fauna von Madeira. Abh. senckenberg. naturf. Ges., 469, 1-93, 1943.

Morais, J. C. DE: A Ilha de Porto Santo e as suas rochas. - Mem. Not. Publ. Mus. Min. Geol. Univ. Coimbra, 12, 1-48, 1943.

MülleR, G. \& TIETz, G.: Recent dolomitization of Quaternary biocalcarenites from Fuerteventura (Canary Islands). - Contr. Min. Petrol., 13, 89-96, 1966.

Pereira, A. C. N.: Ilhas de Zargo. - 1, Ed. Câmara Municipal, Funchal 1956 (lag uns nicht vor).

Pilkey, O. H.: The size distribution and mineralogy of the carbonate fraction of United States south Atlantic shelf and upper slope sediments. - Mar. Geol., 2, 121-136, 1964. 
Rohdenburg, H. \& SAbelberg, U.: „Kalkkrusten“ und ihr klimatischer Aussagewert - neue Beobachtungen aus Spanien und Nordafrika. - Göttinger Bodenkdl. Ber., 7, 3-26, 1969a.

- : Zur landschaftsökologisch-bodengeographischen und klimagenetisch-geomorphologischen Stellung des westlichen Mediterrangebietes. - Göttinger Bodenkdl. Ber., 7, 27-47, 1969b.

Rothe, P.: Dolomitization of biocalcarenites of Late-Tertiary age from northern Lanzarote (Canary Islands). - Recent Developments in Carbonate Sedimentology in Central Europe ed. G. Mülleer \& Friedman, G. M.), 38-45, Berlin 1968.

Sanders, J. E. \& Friedman, G. M.: Origin and occurrence of limestones. - Developm. Sedimentol. 9 A, (ed. G. V. Chilingar et al.), 169-348, Amsterdam 1967.

Sayles, R. W.: Bermuda during the ice-age. - Proc. Am. Acad. Arts Sci., 66, 381-467, 1931.

SCHMincke, H. U.: Faulting versus erosion and the reconstruction of the Mid-Miocene shield volcano of Gran Canaria. - Geol. Mitt., 8, 23-50, Aachen 1968.

Schwarzbach, M.: Geologische Tätigkeit des Windes. - Lehrb. allg. Geol. (ed. R. Brinkmann) I, 250-280, Stuttgart 1964.

Stearns, C. E. \& Thurber, D. L.: Th230-U234 dates of late Pleistocene marine fossils from the Mediterranean and Maroccan littorals. - Quaternaria, 7, 29-42, 1965.

Van Zinderen Bakker, E. M.: The pluvial theory - an evaluation in the light of new evidence, especially for Africa. - The Paleobot., 15, 128-134, Lucknow 1966.

WEST, J. A.: A rapid method for thin-sectioning clays. - Sedimentology, 6, 339-341, 1966.

Wiche, K.: Beiträge zur Formenentwicklung der Sierren am unteren Segura (Südostspanien). Mitt. Ósterr. Geogr. Ges., 103, 125-157, 1961.

Woldstedt, P.: Quartär. - Hdb. der stratigraphischen Geologie Bd. II, 263 S., Stuttgart 1969.

Zilch, A.: Euthyneura (Teil 2 von Wenz, W.: Gastropoda). - Hdb. Paläozool., 6 (2), 1-834, Berlin 1959-1960.

Topographische Karten: Carta Corográfica da Ilha de Porto Santo 1:25000, 1938. Seekarte „Madeira-Inseln“ (Nr. 243) 1 : 150 000, Hamburg 1969.

Manuskr. eingeg. 9. 3. 1970.

Anschrift der Verf.: Dr. J. Lietz und Prof. Dr. M. Schwarzbach, Geol. Institut der Universität, 5 Köln, Zülpicher Straße 49. 